\title{
Effects of Figural and Numerical Presentation Formats on Growing Pattern Performance
}

\author{
Marta K. Mielicki ${ }^{1}$ (1) , Charlies J. Fitzsimmons ${ }^{1}$ (1) , Lauren H. Woodbury ${ }^{1}$, Hannah Marshal $^{1}$, Dake Zhang ${ }^{2}$, \\ Ferdinand D. Rivera ${ }^{3}$, Clarissa A. Thompson ${ }^{1}$ (C) \\ [1] Department of Psychological Sciences, Kent State University, Kent, OH, USA. [2] Graduate School of Education, Rutgers University, New Brunswick, N7, USA. \\ [3] Department of Mathematics \& Statistics, San fose State University, San fose, CA, USA.
}

Journal of Numerical Cognition, 2021, Vol. 7(2), 125-155, https://doi.org/10.5964/jnc.6945

Received: 2020-10-02 • Accepted: 2021-03-12 • Published (VoR): 2021-07-23

Handling Editor: Firat Soylu, University of Alabama, Tuscaloosa, AL, USA

Corresponding Author: Marta K. Mielicki, Department of Psychological Sciences, Kent State University, P.O. Box 5190, Kent, OH 44242-0001, USA. E-mail: mmielick@kent.edu

\begin{abstract}
Prior work exploring preschool-aged children's reasoning with repeating patterns has shown that patterning ability is an important predictor of math achievement; however, there is limited research exploring older children's growing pattern task performance. The current study tested whether presentation format impacts performance on growing pattern problems, and whether the effects of presentation format extend to transfer word problems for which no patterns are provided. Sixth grade students were randomly assigned to complete several growing pattern tasks in one of three presentation formats (figures, sequences of values, or tables of values), and later completed transfer story problems with no figures, sequences, or tables provided. Findings suggest that presenting growing patterns as figures can benefit performance, although these benefits may depend on both pattern type and task. No differences were observed in performance on transfer problems, likely because students rarely spontaneously generated figures. Additional exploratory analyses suggest that performance on growing pattern problems may be related to both standardized math ability and fraction task performance, whereas inhibitory control may only be related to performance for specific patterning tasks. These findings have implications for educators because describing/expressing patterns is critical to algebra and higher-level mathematics.
\end{abstract}

\section{Keywords}

growing patterns, presentation format, transfer, relational reasoning, algebra

Mathematics ability is related to several important life outcomes, including better-informed health and financial choices (Peters et al., 2019; Reyna, Nelson, Han, \& Dieckmann, 2009). Math achievement in childhood is linked to better college completion rates, higher earning potential, and higher socio-economic status lasting into adulthood (Kilpatrick, Swafford, \& Findell, 2001; Ritchie \& Bates, 2013). Notably, algebra is considered to be a gatekeeper both for college and the job market. Students without a strong foundation of algebraic knowledge face exclusion from careers in science, technology, engineering, and mathematics (STEM) fields (LaFave, 2019; National Mathematics Advisory Panel [NMAP], 2008; Schoenfeld, 1995). Therefore, there has been a push to begin algebra instruction earlier, and one potential way to encourage algebraic thinking with younger children is through working with patterns.

Two main types of patterns have been the focus of existing research: repeating patterns and growing patterns. In repeating patterns, a set of elements, the unit of repeat, is repeated indefinitely. For instance, in the repeating 
pattern $A B C A B C A B C$, the unit of repeat, $A B C$, consists of the elements $A, B$, and $C$. Growing patterns increase or decrease in well-defined, predictable ways, and can be expressed recursively (e.g., $f(x)=1+4+4+4 \ldots$ ) or using function-based rules or formal algebraic expressions (e.g., $f(x)=4 x+1$ ). In the growing pattern ABAABAAABAAAAB, there is one element, $\mathrm{B}$, that remains constant and one element, $\mathrm{A}$, that increases by a unit of one for each stage of the pattern. Growing patterns may have specific implications for algebra learning and represent an intriguing opportunity to introduce algebraic thinking even in early grades (McGarvey, 2012; Stephens, Ellis, Blanton, \& Brizuela, 2017; Warren \& Cooper, 2008).

\section{Patterning, Math Achievement, and Algebraic Understanding}

A growing body of work supports a connection between patterning ability and math outcomes; most of this research has focused on preschoolers completing repeating patterns (Burgoyne, Malone, Lervag, \& Hulme, 2019; Fyfe, Evans, Matz, Hunt, \& Alibali, 2017; Nguyen et al., 2016; Rittle-Johnson, Zippert, \& Boice 2019; Zippert, Clayback, \& RittleJohnson, 2019). Some work has also tested the relation between growing patterns and math achievement (Hendricks, Trueblood, \& Pasnak 2006; Kidd et al., 2013; Kidd et al., 2014; Papic, Mulligan, \& Mitchelmore, 2011; Pasnak et al., 2016; Lee, Ng, Bull, Pe, \& Ho, 2011; Wijns, Verschaffel, De Smedt, De Keyser, \& Torbeyns, 2021). Growing patterns may have specific implications for algebra (Lee et al., 2011; McGarvey, 2012; Stephens et al., 2017; Warren \& Cooper, 2008) in part because they represent relations between input and output values. Understanding these types of relations is critical for understanding the concept of a function (Stephens et al., 2017), an important topic in high school mathematics (Common Core Standards Writing Team, 2013). Children's understanding of growing patterns has been understudied relative to repeating patterns (MacKay \& De Smedt, 2019; Wijns, Torbeyns, Bakker, De Smedt, \& Verschaffel, 2019). The current study addresses this gap in the research by exploring sixth grade students' performance on growing pattern problems specifically.

In the remainder of this introduction, we provide a brief review of the literature motivating our primary research question: how does the presentation format of growing pattern tasks (e.g., visual versus numerical) impact performance and transfer? Then, we review relevant research motivating our exploratory analyses for our second research question: what are the relations between growing pattern task performance and individual differences including inhibitory control, fraction task performance, and math ability? In our study, 72 sixth-grade participants were randomly assigned to complete growing pattern tasks in one of three experimental conditions (numerical sequences, tables, or figures). Next, all participants completed transfer problems, in the form of algebra story problems with no sequences, tables, or figures provided, and individual difference measures. Our findings suggest that the way patterning tasks are presented may impact performance, but these effects may vary depending on the type of pattern and the type of task.

\section{Effects of Presentation Format in Problem Solving}

Growing patterns can be presented to learners in different formats, such as tables of input and output values, sequences of values, or figures (see Appendix A). Most research on children's patterning knowledge focuses on visual patterns, both for repeating patterns (Fyfe, McNeil, \& Rittle-Johnson, 2015; Papic et al., 2011; Rittle-Johnson, Fyfe, Loehr, \& Miller, 2015; Rittle-Johnson, Fyfe, McLean, \& McEldoon, 2013) and for growing patterns (El Mouhayar \& Jurdak, 2016; Jurdak \& El Mouhayar, 2014). Even five-year-olds can generalize growing patterns presented as figures (cf., Stephens et al., 2017). Using concrete or visual materials (i.e., physical tiles or pictures of patterns) may help learners make the connection between position number and number of units in a growing pattern (Warren \& Cooper, 2008). For example, in the patterns in Figure 1, children must recognize that the first stage of the pattern contains 5 squares, the second stage contains 9 squares, etc. To date, there is no research comparing how different pattern presentation formats impact students' performance on growing pattern tasks or on subsequent transfer problems. However, presentation format has been shown to affect performance on math tasks in non-patterning domains. 
Presenting mathematical problems or tasks in different ways can impact performance. When solving a math problem, a learner must first form an accurate internal representation by encoding relevant problem elements before selecting and executing a solution strategy. Thus, the nature of a learner's internal representation can impact strategy selection or which prior knowledge is applied during problem solving (Cummins, Kintsch, Reusser, \& Weimer, 1988; Hall, Kibler, Wenger, \& Truxaw, 1989). Presentation format can make certain problem elements more or less salient (Alibali, Crooks, \& McNeil, 2018; Alibali, McNeil, \& Perrott, 1998; Siegler \& Thompson, 2014), and perceptual features can change how learners encode elements of the problem, which in turn may impact solution strategies. Features of problem format (e.g., presenting the same algebra problems as story problems vs. equations, or presenting fraction magnitudes using number lines vs. circle area models) impact learning and performance on tasks featuring fractions and ratios (Boyer, Levine, \& Huttenlocher, 2008; Sidney \& Thompson, 2019; Sidney, Thompson, \& Rivera, 2019; Siegler \& Thompson, 2014) and algebra (Chu, Rittle-Johnson, \& Fyfe, 2017; Koedinger \& Nathan, 2004; Mielicki \& Wiley, 2016).

\section{How Might Pattern Presentation Format Impact Patterning Performance?}

Although children can successfully reason with visually presented patterns (usually in the form of a sequence of shapes and colors), there is also evidence that visual format could hinder patterning performance relative to other formats. Preschoolers are less successful at extracting the underlying structure for repeating patterns presented with concrete descriptions referencing the shape or color of the elements in the pattern rather than abstract descriptions (Fyfe et al., 2015). Concrete descriptions may draw children's attention to irrelevant, surface-level features at the expense of pattern abstraction. In addition, children may struggle with identifying which features to attend to with visually presented repeating patterns. For instance, children's performance on a repeating pattern extension task suffered when they had to attend to two dimensions (size and shape) as opposed to one (Fyfe et al., 2017).

We argue that visual format (see Figure 1) is more concrete than numerical format because a figure of a pattern conveys more perceptual information, such as color or shape, compared to the same pattern presented as a sequence or table of numbers (Fyfe \& Nathan, 2019). If children are distracted by perceptual information, this could impede their ability to extract the underlying structure for growing patterns presented as figures. Growing patterns presented as tables or sequences of numbers may be more abstract than patterns presented as figures, which could facilitate patterning performance as the use of abstract labels ( $\mathrm{AAB}$ vs. red, red, blue) did for repeating patterns in Fyfe et al. (2015). On the other hand, it is possible that figural format may help draw children's attention to important features of the underlying function of the pattern, such as a non-zero starting value or constant, which should improve performance on growing pattern tasks.

It is also an open question whether different presentation formats impact performance on transfer problems for which no figure, sequence, or table is provided. Teaching students a mathematical rule using concrete symbols (e.g., $\square$, 目, 目) leads to lower transfer performance than teaching the rule with more abstract symbols (e.g., $\bullet, \bullet$ ), which suggests that using concrete instantiations may impede transfer (Kaminski, Sloutsky, \& Heckler, 2008). In contrast, fading from concrete to abstract symbols during learning leads to better transfer of a mathematical rule than learning with either all concrete or all abstract symbols (McNeil \& Fyfe, 2012). However, even if some concreteness is beneficial for transfer, learners often fail to apply previously learned principles and strategies to new problems without explicit hints to do so (Gick \& Holyoak, 1980; Richland, Zur, \& Holyoak, 2007; Sidney, Thompson, et al., 2019). Moreover, the 
transfer problems used in the current study were algebra story problems, which can be difficult for learners (Koedinger, Alibali, \& Nathan, 2008; Nathan \& Koedinger, 2000; NMAP, 2008), in part because the problem solver has to make decisions about what role the values in the problem play (e.g., assigning values to represent $x$ and $y$ in an equation) before performing calculations (Novick \& Holyoak, 1991; Wollman, 1983). Children's math instruction may contribute to an impulse to calculate (Schiller, 2020), performing operations on values in a problem without consideration of the relations between the values, which may contribute to the difficulty of story problems for children. Thus, it remains an open question whether children who solve growing patterns with figures, relative to sequences and tables, will perform better on challenging story transfer problems in the absence of figures.

\section{How Might Pattern Presentation Format Impact Children's Strategies?}

Presentation format may impact students' choice of strategies to solve patterning tasks. When children and adults reason about growing patterns presented with figures, use of two specific strategies may help them attend to both the constant properties of a pattern as well as the parts that change (Becker \& Rivera, 2006; Rivera \& Becker, 2005). First, the recursive strategy is characterized by trial-and-error and focuses on specific differences between elements in a pattern in an attempt to uncover a constant rate of change between numbers. Those who rely on this approach tend to generate recursive formulas (e.g., $f(x)=1+2+2+2+\ldots$ where the number of 2 s added equals $x$ ) relying primarily on repeated addition. Second, the functional strategy focuses on identifying the relation between the stage of a figure (Figure 1, 2, 3, etc.) and the number of elements in the figure. Those who rely on this strategy can express the relation between stages and elements with formulas more in line with conventional notation of algebraic functions (e.g., $f(x)=2 x+1$ ), and these strategies are characterized by multiplication instead of repeated addition.

Although there is evidence that students may rely on both recursive and functional strategies when reasoning about growing patterns presented with figures (Becker \& Rivera, 2006; El Mouhayar \& Jurdak, 2016; Jurdak \& El Mouhayar, 2014; Rivera \& Becker, 2005), no existing research has compared students' strategies for growing pattern tasks presented with figures relative to other presentation formats (e.g., tables or sequences). Some have claimed that presenting growing patterns as tables may encourage recursive strategies when the input values increase by the same amount (Carraher, Martinez, \& Schliemann, 2008; Warren, 2005), though this claim has not been empirically tested. Moreover, the types of strategies children use may depend on the demands of the specific patterning task (Collins \& Laski, 2015; El Mouhayar \& Jurdak, 2016; Jurdak \& El Mouhayar, 2014; Wijns, Torbeyns, Bakker, et al., 2019). Recursive strategies may be more common for near extension tasks (see Figure 1), which require filling in missing stages in a pattern. Conversely, children may be more likely to rely on functional strategies for far extension tasks, which require extending a pattern to larger stages. Recursive strategies are more computationally demanding for far extension tasks than for near extension tasks, which may lead students to shift to more efficient functional strategies. For example, if asked to find the number of squares in the 37th stage of the pattern shown in Figure 1, the recursive strategy of repeatedly adding four would be much more laborious and error prone than a functional strategy of calculating $(37 \times 4)+1$. It is important to better understand the contexts that elicit different strategies on patterning tasks because these strategies may impact task performance.

\section{Exploring Relations Between Inhibitory Control, Fraction Task Performance, Math Ability, and Growing Pattern Performance}

To address our secondary research question, we consider the role of individual differences in patterning performance based on evidence supporting a link between patterning and math achievement (Burgoyne et al., 2019; Fyfe et al., 2017; Lee et al., 2011; Nguyen et al., 2016; Rittle-Johnson et al., 2019; Zippert et al., 2019). Both patterning and mathematics more generally rely on the ability to consider relations between concepts. Patterning is an "early form of relational reasoning" (Fyfe et al., 2015, p. 927) that involves considering how elements in a pattern relate to one another. Research on children's relational reasoning often relies on patterns as stimuli (Kotovsky \& Gentner, 1996; Son, Smith, \& Goldstone, 2011), relational knowledge predicts performance on repeating patterning tasks (Miller, Rittle-Johnson, Loehr, \& Fyfe, 2016), and repeating patterns have been used to introduce elementary-school children to the relational concept of ratio (Warren \& Cooper, 2007). Mathematics is fundamentally relational (Sidney \& Thompson, 2019), and relational reasoning 
ability is related to math achievement (Richland et al., 2007; Singley \& Bunge, 2014; White, 1998). Although relational reasoning is thought to be important in mathematics generally (Fuchs et al., 2006; Richland, Holyoak, \& Stigler, 2004), it may be particularly important in algebra (DeWolf, Bassok, \& Holyoak, 2016) where generalized arithmetical concepts (e.g., polynomial and exponential expressions) and rules convey relations among quantities (Sfard \& Linchevski, 1994).

Fractions are a specific relational mathematical concept because they entail a relation between parts of a whole and the fraction's whole (Paik \& Mix, 2003) or between the numerator and denominator. Fraction knowledge has also been found to relate to algebra performance (Booth \& Newton, 2012; Booth, Newton, \& Twiss-Garrity, 2014; DeWolf et al., 2016; DeWolf, Bassok, \& Holyoak, 2017; Hurst \& Cordes, 2018; NMAP, 2008). Since fraction knowledge draws on relational reasoning and relates to math achievement, we aimed to explore whether performance on fraction tasks is also correlated with performance in patterning tasks. To our knowledge, no other work has explored a connection between patterning and fraction performance.

A fraction comparison task and a number line estimation task were used in our study. In addition to fractions being inherently relational, fraction tasks may encourage relational thinking in various ways. For instance, in the number line estimation task a child is asked to place the fraction $5 / 6$ on a number line with endpoints of 0 and 1 . The child may consider the relation between the numerator and denominator to estimate the magnitude of the fraction. The child might think about how half of 6 would be 3 , so $5 / 6$ should be more than halfway between 0 and 1 . The child may try to relate her prior experience with whole numbers on number lines when deciding where to place the fraction on the number line (Sidney \& Thompson, 2019) by thinking of the number line as being segmented into 6 parts. The presence of the number line itself may also encourage the child to consider the relation between the symbolic ratio (i.e., the magnitude of the fraction itself) and the non-symbolic ratio (i.e., the visual proportion formed by the part and whole of the number line). Number lines may function as a bridge between symbolic and non-symbolic ratios (Sidney, Thompson, Matthews, \& Hubbard 2017), because the spatial nature of the number line representation taps into an innate non-symbolic ratio processing system (Matthews, Lewis, \& Hubbard, 2016), which can be leveraged to understand symbolic fractions. Thus, the number line estimation task presents many opportunities for engaging in relational thinking. The other task used in this study, the fraction comparison task, entails comparison of two fractions to determine which one is larger. This task taps relational thinking because it requires considering how the numerators and denominators relate in the individual fractions as well as how the fractions relate to each other. Thus, both of the fraction tasks used in this study involve relational thinking.

Patterning ability is thought to be related to relational reasoning ability (Fyfe et al., 2015; Miller et al., 2016); however, studies exploring the link between relational reasoning and patterning have relied primarily on preschoolers completing repeating pattern tasks. Relational thinking may play a larger role in growing patterns, which express a relation between input and output values and are more complex than repeating patterns (MacKay \& De Smedt, 2019). Furthermore, the relational reasoning tasks in prior work have typically been visual pattern tasks (e.g., matrix reasoning tasks with perceptual patterns or match-to-sample tasks where children identify novel instances of a given visual pattern), thus it is not surprising that performance on these tasks relates to patterning ability. A novel contribution of the current study is that we explore the relation between performance on tasks that vary at the surface level, growing patterning tasks and fraction tasks, but both rely on relational reasoning.

Another individual difference that may be related to patterning ability is inhibitory control, or the ability to attend to task-relevant information while ignoring irrelevant information. Inhibitory control predicts overall math ability (Soltész, Goswami, White, \& Szűcs, 2011; St Clair-Thompson \& Gathercole, 2006; Szũcs, Soltész, Jarmi, \& Csepe, 2007), and may be especially important for patterning, which requires attending to features related to the pattern's underlying structure as opposed to irrelevant, and potentially distracting, surface-level features. Although some research involving preschool children and repeating patterns has shown relations between inhibitory control and patterning performance (Collins \& Laski, 2015), this relation is not consistently found (see Wijns, Torbeyns, De Smedt, \& Verschaffel, 2019 for a review). However, growing pattern problems are more complex (Gadzichowski, 2012; Wijns, Torbeyns, Bakker, et al., 2019) and thus may require more inhibitory control. Another possibility is that students may struggle with growing patterns due to an emphasis on repeating patterns in math classes (Wijns, Torbeyns, Bakker, et al., 2019). If this is the case, then success on growing pattern tasks may require inhibition of information relating to repeating patterns, such as inhibiting strategies that focus only on the unit of repeat in favor of strategies that also incorporate elements that remain constant 
throughout stages of the pattern. Furthermore, the relation between inhibitory control and growing pattern problem performance could vary by task (e.g., near extension vs. far extension). As discussed above, success on far extension tasks may depend on learners' ability to inhibit a more accessible recursive strategy in favor of a more efficient functional strategy. Inhibitory control uniquely predicted whether children could successfully solve algebra problems using more sophisticated algebraic strategies instead of less sophisticated arithmetic ones (Khng \& Lee, 2009). Finally, the existing research exploring the relation between patterning and inhibitory control has primarily involved samples of very young children. Like other executive functions, inhibitory control changes across development (Johnson, Blum, \& Giedd, 2009; Luna, Padmanabhan, \& O'Hearn 2010), and the relation between inhibitory control and mathematical ability also changes (Gilmore, Keeble, Richardson, \& Cragg, 2015). Thus, the relation between patterning and inhibitory control may be different for older children than for preschoolers.

Lastly, given the correlational evidence supporting a link between patterning and general math outcomes (Burgoyne et al., 2019; Fyfe et al., 2017; Lee et al., 2011; Nguyen et al., 2016; Rittle-Johnson et al., 2019; Zippert et al., 2019), it is possible that overall math ability, as measured by standardized achievement tests, may also relate to patterning task performance. The current study investigates the relation between growing pattern task performance and standardized math achievement.

\section{Current Study}

The primary goal of the current study was to test whether sixth graders approach patterning tasks differently depending on whether the patterns are presented numerically or with figures. By sixth grade, students have exposure to the Common Core standards in the "Operations and Algebraic Thinking" domain which deal with generating numerical sequences using rules that relate input to output (CCSSM 6.EE.C.9; National Governors Association Center for Best Practices \& Council of Chief State School Officers, 2010). Furthermore, sixth grade is when students are first exposed to variable-based expressions and equations (CCSSM 6.EE.A.2; National Governors Association Center for Best Practices \& Council of Chief State School Officers, 2010). The current study tested whether presentation format impacted growing pattern performance, strategy choice, and subsequent transfer performance on algebraic story problems. Figures may be less abstract than tables or sequences (Fyfe et al., 2017; Fyfe et al., 2015), and thus might draw children's attention toward irrelevant attributes of the pattern (e.g., color or shape) instead of the underlying structure. Alternatively, presenting patterns as figures might lead students to adopt strategies more consistent with a function-based approach (Becker \& Rivera, 2006; Carraher et al., 2008; Rivera, 2010), which could improve performance on the patterning tasks. However, even if figural presentation format encourages functional strategies, it is not clear whether the use of these strategies would carry over to transfer problems (when figures are not provided) because children do not always spontaneously produce visuals beneficial for problem solving (Sidney, Thompson, et al., 2019).

A secondary goal of the current study was to explore the potential relations between patterning and individual differences in inhibitory control, relational reasoning, and math ability. Based on prior work with repeating patterns (Fyfe et al., 2015; Miller et al., 2016), positive correlations were expected among patterning performance, relational reasoning, and math ability.

\section{Method}

\section{Participants}

Participants were recruited from a single intermediate school which reported $24 \%$ of students were eligible for free or reduced lunch. The school provided standardized reading and math scores from the prior school year for each participant. Seventy-two sixth grade students (38\% female; $79 \%$ White) were randomly assigned to one of three conditions (24 per condition): sequence, table, or figure. Eleven participants were excluded ${ }^{1}$ from the analyses of patterning and transfer task performance for not completing all of the problems (sequence condition: $n=2$, table condition: $n=5$, figure condition: $n=4$ ). One participant did not complete the number line estimation task, and another participant had missing data for all of the individual difference measures. The three conditions did not differ in terms of math ability as measured by standardized test performance, $F(2,59)=0.07, p=.93$, performance on a fraction comparison task, $F(2,59)$ 
$=0.48, p=.62$, or performance (i.e., percent absolute error) on a number line estimation task, $F(2,59)=0.14, p=.87$. The conditions also did not differ in performance on a numerical Stroop task, $F(2,59)=0.87, p=.42$, or on a standardized test measuring reading ability, $F(2,59)=0.63, p=.54$. Descriptive statistics for these measures can be found in Table 1 .

Table 1

Descriptive Statistics for Individual Difference Measures

\begin{tabular}{|c|c|c|c|c|c|c|}
\hline \multirow[b]{2}{*}{ Measure } & \multicolumn{2}{|c|}{ Sequence } & \multicolumn{2}{|c|}{ Table } & \multicolumn{2}{|c|}{ Figure } \\
\hline & $M$ & $S D$ & $M$ & $S D$ & $M$ & $S D$ \\
\hline Standardized Math Score & 717.00 & 71.33 & 721.11 & 24.74 & 722.50 & 35.43 \\
\hline Standardized Reading Score & 708.33 & 72.79 & 722.68 & 33.62 & 718.35 & 50.60 \\
\hline Fraction Comparison Proportion Correct & .84 & .13 & .81 & .17 & .86 & .13 \\
\hline Number Line Estimation (PAE) & $26 \%$ & $6 \%$ & $25 \%$ & $4 \%$ & $26 \%$ & $4 \%$ \\
\hline Stroop Task Inhibition RT (ms) & 960 & 150 & 890 & 210 & 900 & 190 \\
\hline
\end{tabular}

Note. PAE = Percent Absolute Error; higher values of PAE indicate lower estimation precision; Inhibition RT = mean reaction time across incongruent trials. For the standardized math and reading scores, scores above 700 indicate proficiency.

\section{Design and Materials}

Participants were taken out of class and run individually in two sessions in a quiet location in their intermediate school. In the first experimental session, children completed growing pattern problems (see Figure 2 for the design and Appendix A for the problems) and transfer problems (Appendix B).

Children were randomly assigned to complete the growing pattern problems in a figural format, sequence format, or a table format. No figures, tables, or sequences were provided for the transfer problems. Initial pilot work indicated that this number of problems was the maximum that could be completed in a single, hour-long session. In the second session, children completed the fraction tasks (fraction comparison and number line estimation), and the inhibitory control task (numerical Stroop) in a randomized order on a laptop using Qualtrics software.

\section{Tasks for Session 1}

Patterning problems - Children completed the same multi-component growing pattern problems (see Appendix A) for three different patterns. The patterns were presented either as figures, sequences of values, or tables of values depending on random assignment to condition. The first pattern had a proportional underlying function (a zero $y$-intercept or starting value; $y=7 x$ ), and the second two patterns had non-proportional underlying functions (a non-zero $y$ intercept; $y=2 x+3$ and $y=4 x+1$ ). Because prior research suggests that adding a constant to a growing pattern increases the difficulty (Friel \& Markworth, 2009), we analyzed performance on proportional and non-proportional patterns

Figure 2

Session 1 Design

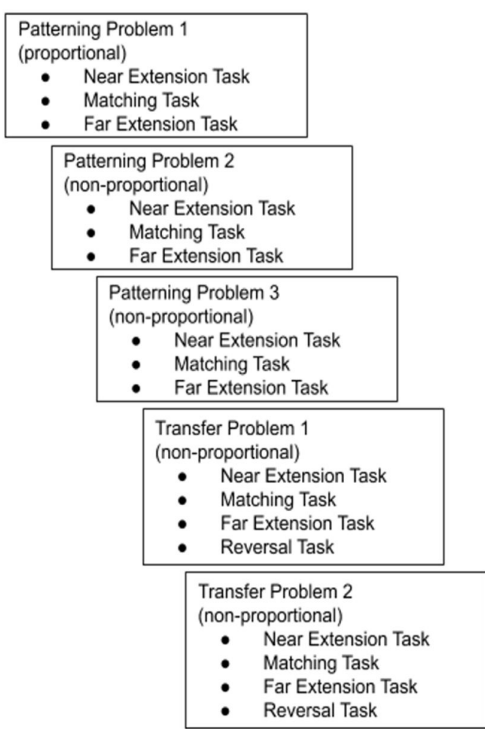
separately. Each pattern featured three tasks: a near extension task, a matching task, and a far extension task, resulting in a total of nine items. For the near extension task, participants filled in the pattern for three of the first six stages. To ensure that providing consecutive stages did not influence performance on the problems, some of the patterns contained consecutive stages and others did not (see Appendix A). For the matching

\footnotetext{
1) Nine of these participants ran out of time, and 2 expressed that they did not wish to continue. These participants did not differ from the participants with complete data on any of the individual difference measures: standardized math and reading scores, relational reasoning (fraction magnitude comparison and number line estimation performance), or inhibitory control (numerical Stroop performance).
} 
task, participants were given two recursive rules generated by hypothetical students and identified which student's rule correctly described the pattern. For the far extension task, participants indicated what a number or figure would be for a stage further along in the pattern (e.g., what would the $43^{\text {rd }}$ number/figure be?). None of the far extension tasks featured "seductive" stage numbers such as 50 or 100, which may encourage incorrect proportional multiplication (Linchevski, Olivier, Sasman, \& Liebenberg, 1998). All tasks also featured the prompt "How do you know?" to encourage students to describe their assumptions about the patterns and to show their work so that their strategies could be qualitatively coded.

Transfer problems - Participants completed the same multi-component transfer problems (see Appendix B), based on two non-proportional underlying functions ( $y=189-7 x$ and $y=24 x+12$, respectively) one of which was decreasing and one increasing. These were story problems, and they were not presented with any numerical or figural patterns. Like the patterning problems, each transfer problem also featured a near extension, matching, and far extension task. In addition, the transfer problems also featured a reversal task, in which participants were asked to indicate what an $x$ value would be for a given $y$ value. This resulted in a total of eight transfer items. As with the patterning problems, all tasks featured a "How do you know?" prompt so that the strategies participants used could be qualitatively coded.

\section{Tasks for Session 2}

Fraction magnitude comparison - Participants completed the same 32 fraction magnitude comparison problems as in Sidney, Thalluri, Buerke, and Thompson (2019). Two fractions with magnitudes between 0 and 1 were shown on the computer screen, and they chose the larger of the two. Accuracy was measured as the proportion of correct responses out of 32 .

Number line estimation - Participants completed the same 20 number line estimation problems as in Sidney, Thalluri, et al. (2019). One fraction was presented on the computer screen at a time, and participants moved a slider between 0 and 5 to indicate the correct location on the number line. The magnitudes of to-be-estimated numbers were spaced evenly throughout the entire 0-5 range. We measured estimation precision with percent absolute error (PAE): the absolute difference between the participant's placement of a response and the correct location of the fraction on a number line, accounting for the numerical range (in this case, 0 to 5). Higher values of PAE indicate lower estimation precision.

Numerical Stroop - Participants completed a numerical Stroop task as a measure of their inhibitory control. As in Fitzsimmons, Thompson, and Sidney (2020), participants selected the physically larger of two digits within the 1-9 range while attempting to ignore numerical magnitude. The Stroop task consisted of a random presentation of 32 congruent (numerical and physical size in the same direction, e.g., ${ }^{1} 2$ ), 32 incongruent (numerical and physical size in opposite directions, e.g., $1^{2}$ ), and 48 neutral (only manipulate the task-relevant dimension of physical size, e.g., $1^{1}$ ) trials with the larger digit appearing equally on the right and left side of the screen. The dependent variable of inhibitory control was operationalized as participants' average response time (RT, in milliseconds) to correct responses on incongruent trials (as in Gómez, Jiménez, Bobadilla, Reyes, \& Dartnell, 2015; Kaufmann et al., 2008; Leibovich, Diesendruck, Rubinsten, \& Henik, 2013). We did not analyze the difference scores between congruent and incongruent trials for two reasons: (1) they are inherently less reliable than scores on congruent or incongruent trials alone (e.g., Cronbach, 1958; Edwards, $1995,2001)$, and (2) it takes participants significantly longer to respond on incongruent than congruent $\left(M_{\mathrm{dif}}=149 \mathrm{~ms}\right.$, $t(68)=12.31, p<.001)$ or neutral trials $\left(M_{\mathrm{dif}}=141 \mathrm{~ms}, t(68)=13.61, p<.001\right)$. Thus, RT on incongruent trials served as a measure of inhibitory control, in this case, inhibition of whole number magnitude information.

\section{Procedure}

The mean time between the two experimental sessions was 19.20 days $(S D=7.32)$. Participants' parents reported their child's sex and ethnicity when they gave consent for their child to participate in the study. The first experimental session lasted approximately one hour. During the first session, all participants completed the same problems in the same order, and the problems were administered with paper and pencil. Once a participant had completed a problem, 
they could not go back and change their responses to earlier problems. During the second experimental session, which lasted about 15 minutes, participants completed the tasks in a randomized order on a laptop using Qualtrics software.

\section{Coding}

\section{Accuracy}

For the near extension task, participants were asked to provide outputs for three stages (see Appendix A) and received a point for each correct response for a maximum of 3 points per near extension task. For all other tasks, participants received one point for a correct response. For both patterning and transfer problems, accuracy was scored as either correct or incorrect, based on whether the correct numerical answer was present somewhere on the page. If a participant indicated a correct answer and then crossed it out and provided a different answer, it was not counted as correct. If a participant crossed out a correct answer, but did not provide an incorrect answer, it was counted as correct. If both a correct and an incorrect answer were provided and neither was crossed out, it was counted as correct. For matching task responses, if a participant indicated that neither alternative rule was correct, their response was scored as incorrect even if they indicated that one of the alternatives was "close" or "almost right" (e.g., "neither but Matt is close" and "technically none are correct but Matt is correct"). For the reversal task on the last transfer problem, participants were given a point for a correct response that featured a remainder (indicating 32.5 or 32 remainder 12). However, they were not given a point if they rounded up (33 instead of 32) because this indicates they did not recognize that the remainder is meaningful (i.e., indicates a starting value).

Because the prompt for the figure condition did not specify that participants should respond with a single numerical answer, several possible responses were coded as correct in order to account for the drawing ability demands that were only present in the figure condition. In the absence of a numerical response, participants' drawings of the figures or verbal descriptions of the figures were coded as correct or incorrect. If participants drew the correct number of squares, their response was considered correct. For the proportional near extension task, if participants indicated an understanding of the pattern of grey and white squares (e.g., "the pattern is 4 gray and 3 white") but did not accurately draw each box, they were also given a point for a correct response. For the non-proportional near extension task, if participants drew a " +1 " next to elements of the previous figure instead of drawing a whole figure as a response or indicated how far the squares would extend (e.g., " +27 on each side") this was counted as correct. Vaguely extended figures (e.g., indicating "and so on") were not counted as correct for the far extension tasks.

Accurate written descriptions of the correct figure were also scored as correct (e.g., "3 blocks empty at the top and 43 pairs of 2 shaded at the bottom" or "there would be 140 shaded blocks and 105 white blocks"), but vague descriptions were not (e.g., "equivalent of the second figure with it's appropriate proportions" or "it would be bigger"). Explicit mention of the starting values for the far extension task in problems 2 and 3 were required in order to receive a point (e.g., "would have 86 shaded squares beneath it" did not receive a point because this response did not indicate there were 3 squares above the 86 squares).

Two raters independently coded the whole data set for accuracy based on these criteria. Percent agreement was calculated by taking the average agreement across each item (17 total across patterning and transfer tasks) and each participant. Percent agreement was $96 \%$, so one rater's coding was used for the following analyses.

\section{Target Strategies}

Using the coding scheme described below, two independent raters coded all responses (regardless of response accuracy) for target strategies. Examples of recursive and functional strategies can be found in Figure 3, and the percentage of students who used each strategy can be found in Table 3 for proportional problems and Table 4 for non-proportional problems. 
Student responses to near extension, far extension, and reversal (transfer problems only) tasks were coded based on the strategies students reported, and the results of this coding were summed separately for each task. The matching task was treated as a recognition task (that is, did students recognize a possible recursive rule), and was only coded for accuracy as described above. However, if the student did not indicate a rule or strategy on any other task within a problem, the student's response to the matching task was taken into consideration when coding the other tasks. Broadly, strategies were coded into two main categories: recursive and functional (see Figure 3 for examples). The recursive and functional codes were not mutually exclusive, and it was possible for a student to demonstrate both recursive and functional strategies within a single task, for instance if the student indicated a rate (e.g., she reads 7 pages a day) but relied on repeated addition instead of multiplying.

Recursive strategies relied primarily on output values to generate a response and could be either full recursive or part recursive. Full Recursive strategies entailed repeated addition of a constant to all intervening output values in order to obtain an answer for one input value (e.g., adding a constant 43 times to find the $43^{\text {rd }}$ output value in a pattern). Part Recursive strategies were only coded for far extension tasks, and entailed addition to, or multiplication of, known output values without repeated addition to all intervening output values (e.g., multiplying the $5^{\text {th }}$ output value in a pattern by seven to get the $35^{\text {th }}$ value in a pattern). These strategies still rely primarily on output values and do not reflect thinking about patterns as a relation between an input and an output but are more efficient than Full Recursive strategies and less prone to error.

Functional strategies, in contrast, rely primarily on multiplicative thinking and demonstrate an understanding of the relation between input values and output values. There were two sub-codes within the functional strategy code, full functional and part functional. Full Functional indicated consideration of both the rate of change and the starting value of a pattern. Part Functional indicated either consideration of only the rate of change (ignoring the starting value completely) or indicated consideration of an incorrect starting value (e.g., $x$ $=1$ not $x=0$ ). These two strategies were coded as Part Functional No Intercept and Part Functional Wrong Intercept, respectively. These two codes for functional strategies were only used for non-proportional problems (2
Figure 3

Examples of Recursive and Functional Strategies

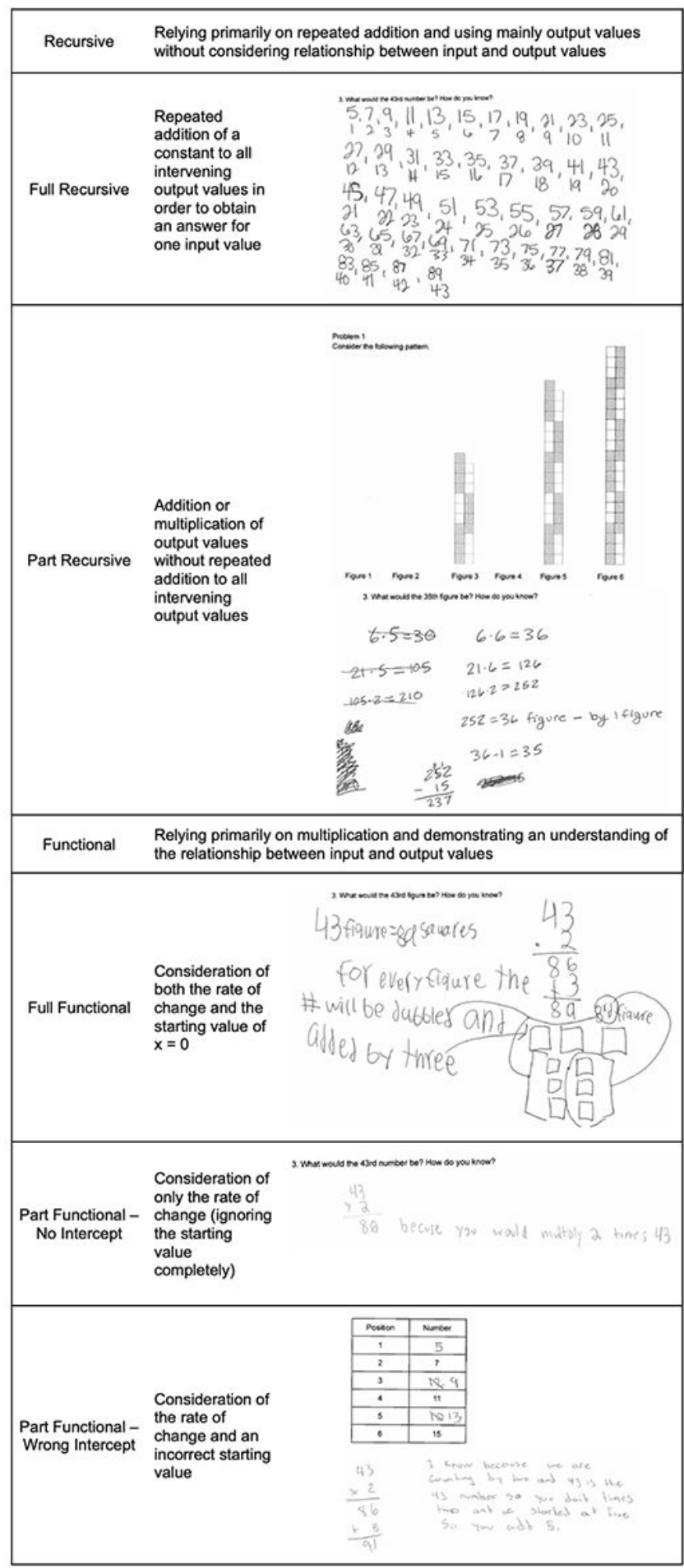

Note. Children's writing in the bottom two panels of the figure read: "because you would multiply 2 times 43" and "I know because we are counting by two and 43 is the 43rd number so you do it times two and we started at five so you add $5 "$. 
and 3, not 1). Problem 1, which had a starting value of 0, only had a Functional code instead of two codes for part and full. Also, near extension tasks did not have a Part Recursive code because the input values were too small for students to rely on this strategy. For reversal tasks in the transfer problems, no Full Recursive code was used because no students relied on this strategy.

For the transfer problems, three additional codes were added in order to track whether participants spontaneously generated a presentation format (sequence, table, figure) while attempting to solve the near and far extension tasks in the transfer problems. To differentiate between a table and simply indicating which response was associated with which input value (e.g., How many pages did she read on the $2^{\text {nd }}, 4^{\text {th }}$, and $6^{\text {th }}$ day?), we only coded a response as having relied on a table if consecutive input values beyond those associated with the response were included. For instance, if the near extension task prompt provided the output values for the first, third, and fifth input values, and the child was required to find output values for the second, fourth, and sixth input values (see Appendix B), a response was only coded as a table if it included input/output pairs for input values $x=1$ through $x=6$. In contrast, a response that only included input/output pairs for input values $x=2, x=4$, and $x=6$ was not coded as a table.

\section{Non-Target Strategies}

Additional codes were included in the coding scheme for responses that could not be interpreted as meaningful strategies. Some strategy codes captured errors that students made when executing a solution procedure. For instance, if a student demonstrated understanding of the rule (either in a recursive or function sense), but incorrectly executed an operation or used the wrong operation (e.g., divided instead of multiplied), this was coded as a Computation Error. If a student demonstrated understanding of the rule but did not answer all parts of the question or missed a step in their calculations (e.g., not dividing the difference between non-consecutive input values in order to get the slope), this was coded as a Missed Step Error. If the student only submitted a response with no justification or calculations provided, this was coded as No Rule. An Other code was used for instances in which the student misunderstood the question, or their response did not fall into any of the above code categories. These non-target codes were analyzed separately (see Appendix C). No condition differences were expected for any of these analyses. However, condition differences did emerge for No Rule codes in patterning problems, $F(2,60)=5.60, p=.006, \eta_{\mathrm{p}}^{2}=.16$. Post-hoc pairwise comparisons with Bonferroni corrections indicated that the figure condition led to more instances of No Rule codes than either of the numerical format conditions, which did not differ. The additional drawing demands may have contributed to slightly more No Rule Errors on pattern problems for the figure condition compared to the other conditions.

We coded for up to 13 possible codes across the non-proportional and proportional problems, though not all codes were relevant for each task. Percent agreement was calculated by taking the average agreement across relevant codes for each task (e.g., Full Recursive, Full Functional, Part Recursive, Part Functional, No Intercept, Wrong Intercept, Computation Error, Missed Step Error, No Rule, Other, and presence of tables, sequences, or figures on the transfer tasks; see Table 4 and C5) across participants. Percent agreement was 91\%, and all disagreements were resolved through discussion, which resulted in the final coding data used for analyses.

\section{Results}

\section{Accuracy}

\section{Proportional Patterning Problem}

Across conditions, we calculated mean percentage correct on the near extension task for each participant by summing the number of points and dividing by three possible points and converting to percentages. Mean percentage correct on the near extension task was $79 \%(S D=38 \%)$. For the matching task, $86.9 \%$ of participants selected the recursive solution that yielded a correct response across conditions, and for the far extension task, $62.3 \%$ of participants indicated a correct response.

To test whether presentation type impacted accuracy on the proportional near extension task, we conducted a one-way ANOVA comparing the percentage correct responses among the three conditions. There was a significant effect of condition, $F(2,58)=14.62, p<.001, \eta_{p}^{2}=.34$. Follow-up pairwise comparisons with Bonferroni corrections 
revealed that the figure condition had lower accuracy on the task $(M=48 \%, S D=44 \%)$ than both numerical conditions, which did not differ (sequence: $M=94 \%, S D=22 \%$; table: $M=95 \%, S D=23 \%$ ).

For the matching task, children's performance did not reliably differ by presentation type, $\chi^{2}(2,61)=4.01, p=.14$, Cramer's $V=.26$. A similar number of children selected the correct recursive rule in the sequence condition $(95.5 \%)$, table condition $(89.5 \%)$ and figure condition $(75.0 \%)$.

For the far extension task, $77.3 \%$ of children in the sequence condition responded correctly, compared to $78.9 \%$ in the table condition and $30.0 \%$ in the figure condition, and the effect of presentation condition was significant, $\chi^{2}(2,61)=$ 13.23, $p=.001$, Cramer's $V=.47$. Post-hoc pairwise comparisons with Bonferroni corrections showed that the numerical presentation conditions did not differ from each other, but the figure condition had lower performance than both the sequence condition $(p<.01)$, and table condition $(p<.01)$.

Taken together, these results suggest that for patterns based on proportional functions, numerical presentation may lead to better performance than figural presentation for both near and far extension tasks. However, there was only a single proportional problem, and the task demands may have been greater in the figural condition than in the numerical condition for two reasons. First, the figure condition entailed drawing demands that were not present in the other conditions. Second, the presence of two different colors of squares in the figure representing the pattern may have impeded children from finding the rate of change by encouraging them to think about the white and shaded squares as separate quantities.

\section{Non-Proportional Problems}

We calculated the percentage of correct responses for each participant for all of the tasks in the non-proportional problems presented with patterns (either figures, tables, or sequences depending on condition) and as story problems without patterns at transfer. For patterning problems, overall mean percentage correct was $84 \%(S D=31 \%)$ for the near extension tasks, $84 \%(S D=30 \%)$ for the matching tasks, and $20 \%(S D=36 \%)$ for the far extension tasks. For transfer problems, overall mean percentage correct was $64 \%(S D=36 \%)$ for the near extension tasks, $80 \%(S D=29 \%)$ for the matching tasks, $21 \%(S D=31 \%)$ for the far extension tasks, and $34 \%(S D=39 \%)$ for the reversal tasks, which were only present at transfer. To test whether presentation type impacted performance on the three tasks for non-proportional problems, we conducted a 3 (condition: sequences, tables, figures) x 3 (task: near extension, far extension, matching) x 2 (problem type: patterning, transfer) mixed ANOVA with accuracy as the dependent variable ${ }^{2}$ (see Table 2).

\section{Table 2}

Percentage Correct by Task and Condition for Non-Proportional Problems

\begin{tabular}{|c|c|c|c|c|c|c|}
\hline \multirow[b]{2}{*}{ Task by Problem Type } & \multicolumn{2}{|c|}{ Sequence } & \multicolumn{2}{|c|}{ Table } & \multicolumn{2}{|c|}{ Figure } \\
\hline & $M$ & $S D$ & $M$ & $S D$ & $\boldsymbol{M}$ & $S D$ \\
\hline \multicolumn{7}{|l|}{ Pattern } \\
\hline Near Extension & $94 \%$ & $18 \%$ & $74 \%$ & $34 \%$ & $84 \%$ & $36 \%$ \\
\hline Matching & $88 \%$ & $27 \%$ & $76 \%$ & $35 \%$ & $88 \%$ & $28 \%$ \\
\hline Far Extension & $5 \%$ & $15 \%$ & $11 \%$ & $28 \%$ & $45 \%$ & $46 \%$ \\
\hline \multicolumn{7}{|l|}{ Transfer } \\
\hline Near Extension & $68 \%$ & $36 \%$ & $68 \%$ & $30 \%$ & $55 \%$ & $43 \%$ \\
\hline Matching & $77 \%$ & $34 \%$ & $84 \%$ & $24 \%$ & $80 \%$ & $30 \%$ \\
\hline Far Extension & $30 \%$ & $33 \%$ & $16 \%$ & $29 \%$ & $15 \%$ & $29 \%$ \\
\hline Reversal & $43 \%$ & $44 \%$ & $37 \%$ & $37 \%$ & $23 \%$ & $34 \%$ \\
\hline
\end{tabular}

2) For the matching and far extension tasks, the results do not change when each matching item and each far extension item are analyzed separately using non-parametric analyses, so the continuous analyses are reported here for ease of comparison across tasks. Item-level accuracy for each task can be found in Appendix C. 
The analysis revealed main effects of task, $F(2,116)=232.93, p<.001, \eta_{\mathrm{p}}^{2}=.80$, and problem type, $F(1,58)=5.11, p=.03$, $\eta_{\mathrm{p}}^{2}=.08$, and no main effect of condition, $F(2,58)=0.59, p=.56$. The main effect of problem type indicates that overall accuracy was lower for transfer problems than patterning problems, which suggests that transfer problems are more difficult and may be tapping separate constructs (e.g., reading comprehension) than patterning problems. All two-way interactions were significant (condition by task: $F(4,116)=2.92, p=.02, \eta_{\mathrm{p}}^{2}=.09$, condition by type: $F(2,58)=4.25$, $p=.02, \eta_{\mathrm{p}}^{2}=.13$, task by type: $\left.F(2,116)=6.35, p<.01, \eta_{\mathrm{p}}^{2}=.10\right)$. These effects were qualified by a three-way interaction, $F(4,116)=5.10, p<.001, \eta_{\mathrm{p}}^{2}=.15$. Follow-up analyses revealed a significant simple two-way interaction of condition and task for patterning problems ${ }^{3}, F(2.98,86.40)=7.46, p<.001, \eta_{\mathrm{p}}^{2}=.09$. When problems were presented with patterns as either figures, tables, or sequences, children performed similarly on the near extension task, $F(2,58)=2.32, p=.11$, and on the matching task, $F(2,58)=1.04, p=.36$. However, pattern presentation format did impact children's performance on the far extension task, $F(2,58)=9.91, p<.001, \eta_{\mathrm{p}}^{2}=.26$. Pairwise comparisons with Bonferroni corrections revealed that this effect was driven by the figure condition outperforming both numerical presentation conditions, which did not differ from each other. These results suggest that for patterns with non-proportional underlying functions, there may be an advantage for figural presentation, specifically for far extension tasks.

In contrast, there was no simple two-way interaction of condition by task for transfer problems, $F(4,116)=1.26$, $p=.29$. An additional one-way ANOVA comparing reversal task performance across conditions also revealed no differences in accuracy, $F(2,58)=1.53, p=.23, \eta_{\mathrm{p}}^{2}=.05$. Taken together, these results suggest that the figural presentation advantage observed for non-proportional far extension pattern problems does not transfer to new problems in which figural presentation is not provided.

\section{Strategies}

\section{Proportional Patterning Problem}

We used Chi-square tests to determine whether children used different strategies in each condition for near and far extension tasks (see Table 3). All follow-up pairwise comparisons are reported with Bonferroni corrections. For the near extension task, condition differences emerged for Full Recursive strategies, $\chi^{2}(2,61)=11.53, p=.003$, Cramer's $V=.44$, and Full Functional strategies, $\chi^{2}(2,61)=31.10, p<.001$, Cramer's $V=.71$. Children in the sequence condition were more likely to rely on Full Recursive strategies than children in the table condition, and children in the table condition were more likely than children in either of the other two conditions to rely on Full Functional strategies.

Table 3

Percentage of Students in Each Condition Who Used Each Strategy by Task for Proportional Patterning Problems

\begin{tabular}{cccc}
\hline Strategy by Task & Sequence & Table & Figure \\
\hline Near Extension & & & \\
Full Recursive & $68 \%$ & $16 \%$ & $40 \%$ \\
Full Functional & $18 \%$ & $84 \%$ & $5 \%$ \\
\hline Far Extension & & & \\
Full Recursive & $0 \%$ & $5 \%$ & $0 \%$ \\
Part Recursive & $9 \%$ & $5 \%$ & $40 \%$ \\
Full Functional & $86 \%$ & $84 \%$ & $30 \%$ \\
\hline
\end{tabular}

For the far extension task, few children in any condition relied on Full Recursive strategies, and there were no differences across conditions, $\chi^{2}(2,61)=2.25 p=.33$. However, there were condition differences for Part Recursive, $\chi^{2}(2,61)=9.82, p$ $<.01$, Cramer's $V=.40$, and Full Functional strategies, $\chi^{2}(2,61)=18.72 p<.001$, Cramer's $V=.55$. Children in the figure condition were more likely to rely on Part Recursive strategies than children in the table condition, and children in the

3) When the degrees of freedom are not whole numbers, this indicates corrections for sphericity assumption violations. 
figure condition were also less likely to rely on Full Functional strategies than children in either of the two numerical format conditions. As with the difference in performance on the proportional near and far extension tasks for the figure condition relative to the other two conditions, the difference in Full Functional strategy use may be due to the shading of the figure in the proportional problem. Several students in the figure condition referred to elements in the pattern based on whether they were shaded or unshaded squares, so the shading may have obscured the overall pattern (i.e., $y=7 \mathrm{x}$ ).

\section{Non-Proportional Problems}

Near and far extension tasks were analyzed separately because of slightly different coding for each task (far extension tasks were coded for Part Recursive strategies, whereas near extension tasks were not), and percentage use for each strategy can be found in Table 4. In order to reduce the number of statistical tests, the No Intercept and Wrong intercept codes were collapsed into a Partial Functional code for both near and far extension tasks. In addition, the Full Recursive and Part Recursive codes were collapsed into an Any Recursive code for far extension tasks.

For near extension tasks, we conducted a 3 (condition: sequences, tables, figures) x 3 (strategy: Full Recursive, Full Functional, Partial Functional) $\mathrm{2}$ (problem type: patterning, transfer) mixed ANOVA to test whether condition impacted strategy use on non-proportional problems. The analysis revealed main effects of strategy, $F(2,116)=199.07, p<.001$, $\eta_{\mathrm{p}}^{2}=.74$, and problem type, $F(1,58)=31.59, p<.001, \eta_{\mathrm{p}}^{2}=.35$, and no main effect of condition, $F(2,58)=0.30, p=.74$. The two-way interaction of strategy by problem type was significant, $F(2,116)=11.66, p<.001, \eta_{\mathrm{p}}^{2}=.17$, and the other two-way interactions were not (condition by problem type: $F(2,58)=2.44, p=.10$, condition by strategy: $F(4,116)=$ $2.18, p=.08$ ). All of these effects were qualified by a three-way interaction, $F(4,116)=4.70, p<.01, \eta_{\mathrm{p}}^{2}=.14$. Similar to the accuracy findings, follow-up analyses revealed a significant simple two-way interaction of condition and strategy for patterning problems, $F(3.24,93.8)=5.07, p<.01, \eta_{\mathrm{p}}^{2}=.15$. When problems were presented with patterns as either figures, tables, or sequences, condition differences emerged in the use of Full Recursive, $F(2,58)=4.53, p=.01, \eta_{\mathrm{p}}^{2}=.14$, and Full Functional strategies, $F(2,58)=4.33, p=.02, \eta_{\mathrm{p}}^{2}=.13$, but not Partial Functional strategies, $F(2,58)=1.37$, $p=.26$. Follow-up pairwise comparisons with Bonferroni corrections revealed that children in the figure condition relied on Full Recursive strategies less frequently and relied on Full Functional strategies more frequently than children in the sequence condition. For transfer problems, the simple two-way interaction was not significant, $F(3.44,99.6)=1.78$, $p=.15$, suggesting that strategy use did not vary by condition when near extension problems were not presented with accompanying patterns.

For the far extension tasks, a 3 (condition: sequences, tables, figures) x 3 (strategy: Any Recursive, Full Functional, Partial Functional) x 2 (problem type: patterning, transfer) mixed ANOVA revealed main effects of strategy, $F(2,116)=$ $17.20, p<.001, \eta_{\mathrm{p}}^{2}=.23$, and problem type, $F(1,58)=14.31, p<.001, \eta_{\mathrm{p}}^{2}=.20$, and no main effect of condition, $F(2,58)=$ $1.08, p=.35$. The two-way interaction of condition by strategy: $F(4,116)=6.91, p<.001, \eta_{\mathrm{p}}^{2}=.19$, was significant, but the condition by problem type, $F(2,58)=1.85, p=.17$, and strategy by problem type, $F(2,116)=2.27, p=.11$, interactions were not. Once again, all of these effects were qualified by a three-way interaction, $F(4,116)=10.61, p<.001, \eta_{\mathrm{p}}^{2}=.27$. Follow-up analyses again revealed a significant simple two-way interaction of condition and strategy for patterning problems, $F(3.54,103)=16.90, p<.001, \eta_{\mathrm{p}}^{2}=.37$. When problems were presented with accompanying patterns, condition differences emerged in the use of Full Functional, $F(2,58)=28.80, p<.001, \eta_{\mathrm{p}}^{2}=.50$, and Partial Functional strategies, $F(2$, $58)=3.36, p=.04, \eta_{\mathrm{p}}^{2}=.10$, but not Any Recursive strategies, $F(2,58)=2.51, p=.09$. Children in the figure condition used Full Functional strategies more frequently than children in the other two conditions, which did not differ. Moreover, the children in the figure condition were less likely to ignore the starting value or rely on a starting value other than $\mathrm{x}=0$ compared to children in the other conditions, which did not differ.

Once again, there was no simple two-way interaction of condition and strategy at transfer, $F(4,116)=0.43, p=.79$, suggesting that there were no condition differences in strategy use for far extension transfer problems. Additional one-way ANOVAs were conducted to determine whether strategy use varied by condition for reversal tasks (see Table 5). Condition differences did not emerge in strategy use on the reversal tasks (Recursive: $F(4,58)=0.85, p=.43 ;$ Full Functional: $F(2,58)=1.01, p=.37$; Partial Functional: $F(2,58)=1.54, p=.22)$.

Finally, we examined the use of spontaneously generated patterns (e.g., drawing a pattern or generating a table of values) at transfer. Students rarely spontaneously generated a pattern in any format when solving transfer problems, and this did not vary by condition. One student in the sequence condition generated a sequence for one of the near 
extension tasks. One student in the figure condition generated a figure for the reversal task in the second transfer problem. Otherwise, tables were the main type of format that students generated, and these were generated primarily for the near extension tasks. Three students (one in each condition) created a table for the first transfer problem, and six students (three in the sequence condition, two in the table condition, and one in the figure condition) created a table for the second transfer problem.

Table 4

Percentage of Students in Each Condition Who Used Each Strategy by Task for Non-Proportional Patterning and Transfer Problems

\begin{tabular}{|c|c|c|c|c|c|c|}
\hline \multirow[b]{2}{*}{ Strategy by Task } & \multicolumn{3}{|c|}{ Pattern } & \multicolumn{3}{|c|}{ Transfer } \\
\hline & Sequence & Table & Figure & Sequence & Table & Figure \\
\hline \multicolumn{7}{|l|}{ Near Extension } \\
\hline Full Recursive & $89 \%$ & $74 \%$ & $55 \%$ & $73 \%$ & $87 \%$ & $85 \%$ \\
\hline Full Functional & $0 \%$ & $8 \%$ & $20 \%$ & $5 \%$ & $5 \%$ & $3 \%$ \\
\hline Part Functional - No Intercept & $0 \%$ & $5 \%$ & $8 \%$ & $34 \%$ & $24 \%$ & $45 \%$ \\
\hline Part Functional - Wrong Intercept & $0 \%$ & $3 \%$ & $0 \%$ & $0 \%$ & $0 \%$ & $3 \%$ \\
\hline \multicolumn{7}{|l|}{ Far Extension } \\
\hline Full Recursive & $0 \%$ & $11 \%$ & $3 \%$ & $0 \%$ & $5 \%$ & $0 \%$ \\
\hline Part Recursive & $19 \%$ & $13 \%$ & $0 \%$ & $41 \%$ & $16 \%$ & $28 \%$ \\
\hline Full Functional & $2 \%$ & $11 \%$ & $68 \%$ & $23 \%$ & $24 \%$ & $23 \%$ \\
\hline Part Functional - No Intercept & $61 \%$ & $37 \%$ & $10 \%$ & $30 \%$ & $45 \%$ & $25 \%$ \\
\hline Part Functional - Wrong Intercept & $14 \%$ & $24 \%$ & $0 \%$ & $27 \%$ & $11 \%$ & $30 \%$ \\
\hline \multicolumn{7}{|l|}{ Reversal } \\
\hline Part Recursive & - & - & - & $53 \%$ & $39 \%$ & $48 \%$ \\
\hline Full Functional & - & - & - & $28 \%$ & $37 \%$ & $20 \%$ \\
\hline Part Functional - No Intercept & - & - & - & $19 \%$ & $24 \%$ & $25 \%$ \\
\hline Part Functional - Wrong Intercept & - & - & - & $21 \%$ & $3 \%$ & $20 \%$ \\
\hline
\end{tabular}

\section{Exploratory Analyses of Individual Difference Measures}

Although this study lacked the sample size to adequately explore how these individual difference measures might predict performance on each of the patterning tasks with regression analyses ${ }^{4}$, the correlations between the measures may still be informative and represent a first step towards better understanding the relation between inhibitory control, fraction task performance, math ability, and performance on the three types of growing pattern tasks. Correlations between measures can be found in Table 5. For a sample size of 60 and $\alpha=.05$, a correlation above .25 is unlikely to be observed by chance. There was a significant negative correlation between RT on the incongruent trials of the numerical Stroop task and performance on the far extension tasks, but no correlation between numerical Stroop and either of the other patterning tasks. This suggests that inhibitory control may be related to performance on far extension tasks specifically. This result is consistent with the idea that in order to be successful on far extension tasks, children may need to inhibit recursive strategies in favor of functional ones.

Performance on the number line estimation task, fraction comparison task, and the math ability measure were related to performance for each of the three patterning tasks. The strength of the correlations among fraction task performance, math ability, and patterning performance was similar for both the near extension and matching tasks. For the far extension task, however, these correlations were slightly weaker. This could be due to a higher likelihood of computation errors for far extension tasks, or children's reliance on different strategies across the patterning tasks. Performance on the near extension and matching tasks was highly related, and children tended to rely heavily on

4) Using G*Power 3.1.9.2 (Faul, Erdfelder, Buchner, \& Lang, 2009), a sample of 85 participants would be required for $80 \%$ power in detecting a medium effect size (defined as $f^{2}=.15$ ) with four predictors. 
recursive strategies for both of these tasks. In contrast, the relation between near and far extension performance was weaker, and there was no relation between matching and far extension performance. It is possible that performance on near extension and matching tasks, for which children tended to use recursive strategies, relies more on magnitude understanding, but also less on inhibitory control, compared to performance on far extension tasks. Overall, these results suggest that for growing pattern tasks, math ability and fraction task performance have similar relations to patterning performance.

\section{Table 5}

Correlations Between Patterning Task Performance and Individual Difference Measures

\begin{tabular}{|c|c|c|c|c|c|c|c|}
\hline Measure & 1 & 2 & 3 & 4 & 5 & 6 & 7 \\
\hline 1. Numerical Stroop & - & $-.45^{\star *}$ & $.31^{*}$ & $-.35^{* *}$ & -.22 & -.15 & $-.26^{*}$ \\
\hline 2. Fraction Comparison & & - & $-.53^{\star *}$ & $.52^{* *}$ & $.47^{* *}$ & $.38^{* *}$ & $.31^{*}$ \\
\hline 3. Number Line Estimation & & & - & $-.75^{* *}$ & $-.41^{* *}$ & $-.51^{* *}$ & $-.29^{*}$ \\
\hline 4. Standardized Math & & & & - & $.47^{* *}$ & $.56^{* *}$ & $.29^{*}$ \\
\hline 5. Near Extension & & & & & - & $.81^{* *}$ & $.28^{*}$ \\
\hline 6. Matching & & & & & & - & .21 \\
\hline 7. Far Extension & & & & & & & - \\
\hline
\end{tabular}

Note. Due to one participant missing data for all individual difference measures, and another missing data for the number line estimation task, Ns for the correlations range from 59 (for correlations with the number line estimation task) to 60 .

${ }^{*} p<.05 .{ }^{* *} p<.01$.

\section{Discussion}

The primary goal of the current study was to test the effect of pattern presentation format on performance and strategy choice for patterning tasks presented in either figural or numerical format and on subsequent transfer problems with no accompanying figural or numerical patterns. Consistent with prior work in other domains of mathematics (Boyer et al., 2008; Chu et al., 2017; Koedinger \& Nathan, 2004; Mielicki \& Wiley, 2016; Sidney \& Thompson, 2019; Sidney, Thompson, et al., 2019; Siegler \& Thompson, 2014), presentation format in the current study impacted sixth grade students' performance on growing pattern problems. The effect of presentation format depended on the type of patterning task and whether the mathematical function underlying the pattern was proportional or not. For the proportional pattern, children in the figure condition performed worse on both near and far extension tasks than children in both numerical presentation format conditions. Children performed similarly on the near extension task for non-proportional patterns. For the far extension task, however, children in the figure condition outperformed children in both of the numerical format conditions. The combination of accuracy analyses for all tasks and detailed strategy coding of 61 participants' open-ended responses across 12 near extension, far extension, and reversal items provided converging evidence and valuable insights into how students approach growing pattern problems.

Analysis of the strategy coding for participants' open-ended explanations for their solutions revealed that presentation format also impacted students' choice of strategies for solving growing pattern problems. This effect was most apparent in the far extension tasks for the non-proportional patterns. For these tasks, figural presentation format facilitated the use of function-based strategies, which are more efficient and more aligned with expert thinking compared to recursive strategies. Further, presenting non-proportional far extension tasks with figures seemed to help students attend to the correct starting values for these problems. Taken together, the differences in strategy use and performance suggest an advantage of presenting patterning tasks in figure format, specifically for far extension tasks with non-proportional underlying functions. However, children's lower performance in the figure condition on the near and far extension tasks for the proportional problem relative to the other two conditions suggests one of two possibilities. Either the presence of figures themselves hurt performance, or some specific features of the figures hurt performance. Because the findings of the current study are based on participant responses for three open-ended questions for a single proportional pattern with a single associated figure, these two possibilities require further exploration. 
The differential effects of figures for proportional and non-proportional growing patterns suggest that the specific surface-level features of the figures may be important. In the case of non-proportional patterns, these features may have enhanced encoding of relevant pattern features, but for the proportional pattern these features may have impeded encoding of the underlying relation between stages of the pattern and the number of elements in the figure. In the proportional pattern used in the current study, the figure was shaded in such a way as to potentially obscure the most efficient expression of the underlying function (i.e., $y=7 x$ instead of $y=3 x+4 x$ ). Strategy reports from students in the figure condition support this possibility. Several students chose to express the underlying pattern in terms of the shaded and unshaded squares rather than in terms of the total number of squares. In contrast, students in the table and sequence conditions may have been able to discern the most efficient expression of the underlying function more easily without additional distraction from surface features of the presentation format.

Although the shading of the figures may have hurt performance on the proportional pattern tasks, presenting the non-proportional patterns with figures helped performance and encouraged more frequent use of functional strategies on the near and far extension tasks. Again, there may be two possible explanations for this effect. The mere presence of a figure may be beneficial, or figures with certain visual features that specifically guide attention to important aspects of the pattern may be driving the benefit. For the non-proportional problems in the current study, the shading of the squares in the figures may have helped draw students' attention to the starting value of the pattern, which was always shaded differently than the part of the pattern that varied. It is not clear whether students would have been more likely to attend to the starting values in these problems if the figures had not been shaded in such a way as to highlight the starting values. Friel and Markworth (2009) suggest that shading the starting value, or constant term, in a different color than the rest of the pattern may help make non-proportional patterns easier for students by making the constant more salient. Other work has also demonstrated that making problem features more salient can benefit problem solving performance. For example, visually highlighting the equal sign in mathematical equivalence problems (such as $3+4+5=3+\ldots$ ) by presenting it in red ink helped fourth-grade students generate correct strategies for solving these types of problems on subsequent tests (Alibali et al., 2018). Alibali and colleagues attribute this finding to the highlighting making the equal sign more salient, and thus helping learners to encode it. For equivalence problems, consistent encoding of the equal sign may help learners avoid adopting a common incorrect "add all" strategy and may thus encourage learners to rely on correct strategies instead. It is possible that the figures used in the current study also highlighted the starting values for the non-proportional patterns in a similar way as the equal sign in Alibali et al. (2018), which may have led to the figure condition's advantage in performance. Future research should explore how specific surface features of visual representation, such as shading or configuration of elements, may benefit or hinder performance on growing pattern tasks and how strategy choice may be affected by these features.

Some additional differences between the figure condition and the two numerical conditions may warrant additional exploration in future research. The figures used in this study may have been more variable than sequences or tables in terms of visual features since there was a different arrangement of squares for each pattern. Although shape is a salient perceptual feature (e.g., Smith, 2003), the tables and sequences also differed in perceptual features (i.e., the specific Arabic numerals) across each pattern. More research is needed to determine how specific perceptual features in different formats might impact patterning performance.

Presenting patterns as figures led to more variability in patterning task performance compared to presenting patterns numerically, and there are a number of possible reasons for this. The figure condition did impose drawing demands that were not present in the other conditions, and this may have contributed to greater variability in performance when patterns were presented with figures as opposed to tables or sequences of values. Related to these additional demands, the figure condition may have introduced some ambiguity about how children should indicate a response for the tasks, as evidenced by slightly more instances of No Rule codes in the figure condition relative to the other conditions. Figures may encourage intuitive, implicit reasoning, such that children might be less likely to report an explicit strategy when they were prompted to do so because they had relied on perceptual strategies (Gentner, 1983; Gentner \& Hoyos, 2017), such as noticing similarities (e.g., alternating colors, number of countable, individual objects, proportion matching among figures, etc.) between lower- and higher-stage patterns to extend the growing patterns. Finally, figural presentation format for growing patterns may have been less familiar to students than tables or sequences of values, which may have contributed to greater variability in task performance. Despite this potential 
difference in familiarity, however, figural presentation format still resulted in better performance on far extension tasks than numerical presentation format.

In the current study, differences in performance did not emerge between the two numerical presentation formats on any of the tasks. This may be surprising given that tables included both input and output values which could have helped students identify the underlying functional relation. However, this benefit would depend on whether students attended to the provided input values in the tables. Although there were no differences in performance between the two numerical presentation formats, there was a difference in strategy use, though only for the proportional near extension task. For this task, the sequence presentation format may have led children to rely on recursive strategies and the table presentation format may have led children to rely on functional strategies. Given that this result is based on a single pattern and task, this should be interpreted with caution, but it suggests that for some types of problems it might be advantageous to provide students with tables instead of sequences. Future research could test whether drawing students' attention to the input values might strengthen potential benefits of presenting problems with tables relative to sequences.

Although presentation format had an effect on both performance and strategy use for growing pattern problems, these effects did not transfer to problems presented without accompanying figures, tables, or sequences. No figure condition advantage emerged for near extension or far extension tasks for transfer problems, suggesting that students did not spontaneously leverage benefits of figures when figures were not explicitly provided. Students rarely generated their own presentation format when solving the transfer problems, which is in line with prior work (Sidney, Thompson, et al., 2019). When students spontaneously generated their own presentation format in the current study, it was generally a table. This is likely due to students having more experience with tables as a presentation format relative to sequences or figures. Students in fifth and sixth grade represent patterns as ordered pairs and tables, which they also graph on a coordinate plane to help them learn proportional relationships and functions in the middle grades (CCSMM 5.OA.3, National Governors Association Center for Best Practices \& Council of Chief State School Officers, 2010) and set up rules in the form of equations (CCSSM.6.EE.C.9; National Governors Association Center for Best Practices \& Council of Chief State School Officers, 2010; Common Core Standards Writing Team, 2013).

Given that the findings of the current study suggest an advantage for presenting growing non-proportional patterns with figures and that children are unlikely to spontaneously generate figures when solving transfer problems, how can we get children to generate figures when they are not present? One possible explanation for why students were unlikely to transfer strategies they had used with pattern problems presented with figures to transfer problems may be that they needed to practice with many more patterns before transfer occurred. However, students in the study conducted by Sidney, Thompson, et al. (2019) completed 18 fraction division problems and were still very unlikely to draw diagrams when solving the transfer problems. It took some students in our study nearly a full hour to complete all of the problems in our battery, thus, it is not a realistic goal to have them complete even more problems within one experimental session. Further, decades of research on analogical transfer has shown that people rarely apply previously learned solutions to new problems without explicit hints to do so (e.g., Gick \& Holyoak, 1980). A more viable path for future research may be to provide students with additional instructional support, such as explicit reminders to generate figures or direct instruction about the benefits of drawing figures, in order to generate figures when solving problems for which figures are not provided.

\section{Exploring Individual Differences Related to Growing Pattern Task Performance}

A secondary goal of the current study was to explore how individual differences in math ability, fraction task performance, and inhibitory control relate to performance on growing pattern tasks. These analyses were exploratory, but they provide valuable preliminary insights into how these individual differences may relate to growing pattern performance specifically. Although prior work involving young children who completed repeating pattern tasks has not consistently demonstrated a relation between inhibitory control and patterning performance (Wijns, Torbeyns, De Smedt, et al., 2019), we found evidence for a relation between patterning and inhibitory control in the current study. Specifically, inhibitory control may play a role in performance on far extension tasks, which were more difficult than the other patterning tasks in this study. This could be because children must inhibit more prepotent recursive strategies in favor 
of more efficient functional strategies. In other work, Carraher et al. (2008) encouraged children to move from recursive to functional strategies by skipping input values in a table, which led children to consider the relation between input and output instead of relying on repeated addition. Far extension tasks may encourage children to adaptively choose to employ functional strategies over recursive strategies in a similar way as skipping input values in a table (see Alibali \& Sidney, 2015; Fazio, DeWolf, \& Siegler, 2017; and Sidney, Thalluri, et al., 2019 for adaptive strategy choice in a magnitude comparison task). If students have to inhibit a more prepotent recursive strategy in favor of a more efficient functional strategy, inhibitory control could play a role in far extension task performance. It is also worth noting that the studies included in the review of Wijns, Torbeyns, De Smedt, and colleagues (2019) all relied on non-numerical measures of inhibitory control, whereas the current study used the Numerical Stroop task. It is possible that the more domain-specific inhibitory control measure used in this study would relate to patterning performance more strongly than non-numerical measures used in prior work.

Prior work (Miller et al., 2016), in which young children completed repeating pattern tasks, has shown a connection between patterning ability and relational reasoning, but this had not been explored with growing patterns. Evidence for a connection between performance on fraction tasks, which likely rely on relational reasoning, and patterning performance was found in the current study. Both fraction comparison and number line estimation performance were related to performance on near extension, matching, and far extension tasks. We also found that general math performance related to patterning performance and both of the fraction tasks (i.e., number line estimation and magnitude comparison) as has been found in other work (e.g., Fazio, Bailey, Thompson, \& Siegler, 2014; Siegler \& Thompson, 2014; Siegler, Thompson, \& Schneider, 2011). Given the interrelations among these three measures, it is possible that they all reflect understanding of numerical magnitude, and this understanding may be important for patterning performance. If we accept the premise that mathematics is "fundamentally a system of relationships" (Sidney \& Thompson, 2019, p. 623) it is possible that patterning, number line estimation, and fraction comparison are general mathematical measures that all rely on relational reasoning ability, though perhaps to varying degrees.

Although we found several significant relations among patterning performance, fraction task performance, and a measure of math ability in our exploratory analyses, future studies should endeavor to include a larger sample size, as is customary with individual differences studies, to test the unique contributions of math ability and inhibitory control on growing pattern performance. Understanding the role of individual differences that predict patterning ability may inform potential interventions to improve this ability.

Another important contribution of the current work is the extension of patterning research to older students' performance on growing patterns. The bulk of the existing research on patterning has relied on preschool-aged children's repeating pattern performance (Fyfe et al., 2017; Kidd et al., 2013; Nguyen et al., 2016; Papic et al., 2011; Rittle-Johnson et al., 2019; Zippert et al., 2019), but growing patterns are one way to introduce algebraic thinking in earlier grades (Friel \& Markworth, 2009; Stephens et al., 2017; Walkowiak, 2014), and thus merit more exploration. Rittle-Johnson and colleagues (2013) conducted a systematic investigation of the degrees of difficulty that four-year-olds experienced as they completed repeating pattern tasks. Preschoolers attempted to duplicate a pattern with the same materials, extend a given pattern, abstract a pattern by creating the same pattern using different materials (i.e., shapes or colors), and identify the "unit of repeat" in a pattern. Duplicating a repeating pattern was less difficult than extending the pattern, abstracting a pattern was more difficult than either duplicating or extending a pattern, and identifying the unit of repeat was the most difficult patterning task. In the current study, performance was lower for far extension tasks compared to near extension and matching tasks for both proportional and non-proportional problems, which suggests different levels of difficulty for these tasks. Some recent work has begun addressing these issues with more systematic analyses of task difficulty for growing patterns (Wijns, Torbeyns, Bakker, et al., 2019), similar to the work done by Rittle-Johnson et al. (2013) for repeating patterns. Future work building off of these initial findings would be useful for educators to better understand the specific difficulties students encounter with growing pattern tasks. Given that performance on these patterning tasks was not at ceiling, there is more work to be done to better understand the interrelations among students' conceptual and procedural understanding of growing patterns and algebraic functions. 


\section{Conclusions}

The presentation format of growing pattern problems can impact performance and strategy use on certain patterning tasks. Presenting non-proportional growing patterns with figures may improve performance on far extension tasks by making elements of the pattern more salient, however children are unlikely to spontaneously generate figures when solving transfer problems. The current study also demonstrated preliminary evidence of relations between several individual difference measures--performance on fraction tasks, inhibitory control, and math ability--and patterning performance. These findings have implications for educators because describing/expressing patterns is critical to algebra and higher-level mathematics.

Children's understanding of patterns has received much international attention due to the intriguing connection between patterning and math achievement. This study addresses an important gap in the existing patterning literature and represents important first steps towards better understanding how older students reason with growing patterns. This work also provides a valuable contribution to existing research on how problem presentation format impacts learning and transfer in mathematics. Furthermore, the findings from the current study provide a springboard for future work testing the impact of surface-level features of visual patterns on performance, which may help provide specific guidance to educators seeking to support children's understanding of growing patterns.

Funding: This work was supported in part by the Institute of Education Sciences, U.S. Department of Education award R305A160295, to Kent State University.

Acknowledgments: The authors have no additional (i.e., non-financial) support to report.

Competing Interests: The authors have declared that no competing interests exist.

\section{References}

Alibali, M. W., Crooks, N. M., \& McNeil, N. M. (2018). Perceptual support promotes strategy generation: Evidence from equation solving. British fournal of Developmental Psychology, 36, 153-168. https://doi.org/10.1111/bjdp.12203

Alibali, M. W., McNeil, N. M., \& Perrott, M. A. (1998). What makes children change their minds? Changes in problem encoding lead to changes in strategy selection. In M. A. Gernsbacher \& S. J. Deny (Eds.), Proceedings from the twentieth annual conference of the Cognitive Science Society (pp. 36-41). Erlbaum.

Alibali, M. W., \& Sidney, P. G. (2015). The role of intraindividual variability in learning and cognitive development. In M. Diehl, K. Hooker, \& M. J. Sliwinski (Eds.), Handbook of intraindividual variability across the life span (pp. 84-102). Routledge/Taylor \& Francis Group.

Becker, J. R., \& Rivera, F. (2006). Sixth graders' figural and numerical strategies for generalizing patterns in algebra. In S. Alatorre, J. Cortina, M. Sáiz, \& A. Mendez (Eds.), Proceedings of the 28th annual meeting of the North American chapter of the International Group for the Psychology of Mathematics Education (pp. 95-101). Universidad Pedagógica Nacional.

Booth, J. L., \& Newton, K. J. (2012). Fractions: Could they really be the gatekeeper's doorman? Contemporary Educational Psychology, 37, 247-253. https://doi.org/10.1016/j.cedpsych.2012.07.001

Booth, J. L., Newton, K. J., \& Twiss-Garrity, L. K. (2014). The impact of fraction magnitude knowledge on algebra performance and learning. Journal of Experimental Child Psychology, 118, 110-118. https://doi.org/10.1016/j.jecp.2013.09.001

Boyer, T. W., Levine, S. C., \& Huttenlocher, J. (2008). Development of proportional reasoning: Where young children go wrong. Developmental Psychology, 44, 1478-1490. https://doi.org/10.1037/a0013110

Burgoyne, K., Malone, S., Lervag, A., \& Hulme, C. (2019). Pattern understanding is a predictor of early reading and arithmetic skills. Early Childhood Research Quarterly, 49, 69-80. https://doi.org/10.1016/j.ecresq.2019.06.006

Carraher, D. W., Martinez, M. V., \& Schliemann, A. D. (2008). Early algebra and mathematical generalization. ZDM, 40, 3-22. https://doi.org/10.1007/s11858-007-0067-7

Chu, J., Rittle-Johnson, B., \& Fyfe, E. R. (2017). Diagrams benefit symbolic problem-solving. The British fournal of Educational Psychology, 87, 273-287. https://doi.org/10.1111/bjep.12149 
Collins, M. A., \& Laski, E. V. (2015). Preschoolers' strategies for solving visual pattern tasks. Early Childhood Research Quarterly, 32, 204-214. https://doi.org/10.1016/j.ecresq.2015.04.004

Common Core Standards Writing Team. (2013). Progressions for the common core state standards in mathematics: Fractions. Institute for Mathematics and Education, University of Arizona.

Cronbach, L. J. (1958). Proposals leading to analytic treatment of social perception scores. In R. Tagiuri \& L. Petrullo (Eds.), Person perception and interpersonal behavior (pp. 353-379). Stanford University Press.

Cummins, D. D., Kintsch, W., Reusser, K., \& Weimer, R. (1988). The role of understanding in solving word problems. Cognitive Psychology, 20, 405-438. https://doi.org/10.1016/0010-0285(88)90011-4

DeWolf, M., Bassok, M., \& Holyoak, K. J. (2016). A set for relational reasoning: Facilitation of algebraic modeling by a fraction task. Journal of Experimental Child Psychology, 152, 351-366. https://doi.org/10.1016/j.jecp.2016.06.016

DeWolf, M., Bassok, M., \& Holyoak, K. J. (2017). Numbers as mathematical models: Modeling relations and magnitudes with fractions and decimals. In D. C. Geary, D. B. Berch, R. Ochsendorf, \& K. Mann Koepke (Eds.), Acquisition of complex arithmetic skills and higher-order mathematics concepts (pp. 141-163). Academic Press.

Edwards, J. R. (1995). Alternatives to difference scores as dependent variables in the study of congruence in organizational research. Organizational Behavior and Human Decision Processes, 64, 307-324. https://doi.org/10.1006/obhd.1995.1108

Edwards, J. R. (2001). Ten difference score myths. Organizational Research Methods, 4, 265-287. https://doi.org/10.1177/109442810143005

El Mouhayar, R., \& Jurdak, M. (2016). Variation of student numerical and figural reasoning approaches by pattern generalization type, strategy use and grade level. International fournal of Mathematical Education in Science and Technology, 47, 197-215. https://doi.org/10.1080/0020739X.2015.1068391

Faul, F., Erdfelder, E., Buchner, A., \& Lang, A.-G. (2009). Statistical power analyses using G* Power 3.1: Tests for correlation and regression analyses. Behavior Research Methods, 41, 1149-1160. https://doi.org/10.3758/BRM.41.4.1149

Fazio, L. K., Bailey, D. H., Thompson, C. A., \& Siegler, R. S. (2014). Relations of different types of numerical magnitude representations to each other and to mathematics achievement. fournal of Experimental Child Psychology, 123, 53-72. https://doi.org/10.1016/j.jecp.2014.01.013

Fazio, L. K., DeWolf, M., \& Siegler, R. S. (2017). Strategy use and strategy choice in fraction magnitude comparison. fournal of Experimental Psychology: Learning, Memory, and Cognition, 42, 1-16. https://doi.org/10.1037/xlm0000153

Fitzsimmons, C. J., Thompson, C. A., \& Sidney, P. G. (2020). Do adults treat equivalent fractions equally? Adults' strategies and errors during fraction reasoning. Journal of Experimental Psychology: Learning, Memory, and Cognition, 46(11), $2049-2074$. https://doi.org/10.1037/xlm0000839

Friel, S. N., \& Markworth, K. A. (2009). A framework for analyzing geometric pattern tasks. Mathematics Teaching in the Middle School, 15, 24-33. https://doi.org/10.5951/MTMS.15.1.0024

Fuchs, L. S., Fuchs, D., Compton, D. L., Powell, S. R., Seethaler, P. M., Capizzi, A. M., . . Fletcher, J. M. (2006). The cognitive correlates of third-grade skill in arithmetic, algorithmic computation, and arithmetic word problems. Fournal of Educational Psychology, 98, 29-43. https://doi.org/10.1037/0022-0663.98.1.29

Fyfe, E. R., Evans, J. L., Matz, L. E., Hunt, K. M., \& Alibali, M. W. (2017). Relations between patterning skill and differing aspects of early mathematics knowledge. Cognitive Development, 44, 1-11. https://doi.org/10.1016/j.cogdev.2017.07.003

Fyfe, E. R., McNeil, N. M., \& Rittle-Johnson, B. (2015). Easy as ABCABC: Abstract language facilitates performance on a concrete patterning task. Child Development, 86, 927-935. https://doi.org/10.1111/cdev.12331

Fyfe, E. R., \& Nathan, M. J. (2019). Making "concreteness fading” more concrete as a theory of instruction for promoting transfer. Educational Review, 71, 403-422. https://doi.org/10.1080/00131911.2018.1424116

Gadzichowski, K. M. (2012). Patterning abilities of first grade children: Effects of dimension and type. Creative Education, 3, 632-635. https://doi.org/10.4236/ce.2012.35092

Gentner, D. (1983). Structure-mapping: A theoretical framework for analogy. Cognitive Science, 7, 155-170. https://doi.org/10.1016/S0364-0213(83)80009-3

Gentner, D., \& Hoyos, C. (2017). Analogy and abstraction. Topics in Cognitive Science, 9, 672-693. https://doi.org/10.1111/tops.12278

Gick, M. L., \& Holyoak, K. J. (1980). Analogical problem solving. Cognitive Psychology, 12, 306-355.

https://doi.org/10.1016/0010-0285(80)90013-4 
Gilmore, C., Keeble, S., Richardson, S., \& Cragg, L. (2015). The role of cognitive inhibition in different components of arithmetic. ZDM, 47, 771-782. https://doi.org/10.1007/s11858-014-0659-y

Gómez, D. M., Jiménez, A., Bobadilla, R., Reyes, C., \& Dartnell, P. (2015). The effect of inhibitory control on general mathematics achievement and fraction comparison in middle school children. ZDM, 47, 801-811. https://doi.org/10.1007/s11858-015-0685-4

Hall, R., Kibler, D., Wenger, E., \& Truxaw, C. (1989). Exploring the episodic structure of algebra story problem solving. Cognition and Instruction, 6, 223-283. https://doi.org/10.1207/s1532690xci0603_2

Hendricks, C., Trueblood, L., \& Pasnak, R. (2006). Effects of teaching patterning to 1st-graders. fournal of Research in Childhood Education, 21, 79-89. https://doi.org/10.1080/02568540609594580

Hurst, M., \& Cordes, S. (2018). A systematic investigation of the link between rational number processing and algebra ability. British fournal of Psychology, 109, 99-117. https://doi.org/10.1111/bjop.12244

Johnson, S. B., Blum, R. W., \& Giedd, J. N. (2009). Adolescent maturity and the brain: The promise and pitfalls of neuroscience research in adolescent health policy. The fournal of Adolescent Health, 45, 216-221. https://doi.org/10.1016/j.jadohealth.2009.05.016

Jurdak, M. E., \& El Mouhayar, R. R. (2014). Trends in the development of student level of reasoning in pattern generalization tasks across grade level. Educational Studies in Mathematics, 85, 75-92. https://doi.org/10.1007/s10649-013-9494-2

Kaminski, J. A., Sloutsky, V. M., \& Heckler, A. F. (2008). The advantage of abstract examples in learning math. Science, 320, 454-455. https://doi.org/10.1126/science.1154659

Kaufmann, L., Ischebeck, A., Weiss, E., Koppelstaetter, F., Siedentopf, C., Vogel, S. E., . . Wood, G. (2008). An fMRI study of the numerical Stroop task in individuals with and without minimal cognitive impairment. Cortex, 44, 1248-1255.

https://doi.org/10.1016/j.cortex.2007.11.009

Khng, K. H., \& Lee, K. (2009). Inhibiting interference from prior knowledge: Arithmetic intrusions in algebra word problem solving. Learning and Individual Differences, 19, 262-268. https://doi.org/10.1016/j.lindif.2009.01.004

Kidd, J. K., Carlson, A. G., Gadzichowski, K. M., Boyer, C. E., Gallington, D. A., \& Pasnak, R. (2013). Effects of patterning instruction on the academic achievement of 1st-grade children. Fournal of Research in Childhood Education, 27, 224-238. https://doi.org/10.1080/02568543.2013.766664

Kidd, J. K., Pasnak, R., Gadzichowski, K. M., Gallington, D. A., McKnight, P., Boyer, C. E., \& Carlson, A. (2014). Instructing first-grade children on patterning improves reading and mathematics. Early Education and Development, 25, 134-151. https://doi.org/10.1080/10409289.2013.794448

Kilpatrick, J., Swafford, J., \& Findell, B. (Eds.). (2001). Adding it up: Helping children learn mathematics. Mathematics Learning Study Committee, Center for Education, Division of Behavioral and Social Sciences and Education. National Academy Press. https://doi.org/10.17226/9822

Koedinger, K. R., Alibali, M. W., \& Nathan, M. J. (2008). Trade-offs between grounded and abstract representations: Evidence from algebra problem solving. Cognitive Science, 32, 366-397. https://doi.org/10.1080/03640210701863933

Koedinger, K. R., \& Nathan, M. J. (2004). The real story behind story problems: Effects of representations on quantitative reasoning. fournal of the Learning Sciences, 13, 129-164. https://doi.org/10.1207/s15327809jls1302_1

Kotovsky, L., \& Gentner, D. (1996). Comparison and categorization in the development of relational similarity. Child Development, 67, 2797-2822. https://doi.org/10.1111/j.1467-8624.1996.tb01889.x

LaFave, A. (2019). Algebra I coursetaking and postsecondary enrollment. Data Point. NCES 2019-154. National Center for Education Statistics.

Lee, K., Ng, S. F., Bull, R., Pe, M. L., \& Ho, R. H. M. (2011). Are patterns important? An investigation of the relationships between proficiencies in patterns, computation, executive functioning, and algebraic word problems. fournal of Educational Psychology, 103, 269-281. https://doi.org/10.1037/a0023068

Leibovich, T., Diesendruck, L., Rubinsten, O., \& Henik, A. (2013). The importance of being relevant: Modulation of magnitude representations. Frontiers in Psychology, 4, Article 369. https://doi.org/10.3389/fpsyg.2013.00369

Linchevski, L., Olivier, A., Sasman, M. C., \& Liebenberg, R. (1998). Moments of conflict and moments of conviction in generalising. In A. Olivier \& K. Newstead (Eds.), Proceedings of the 22nd conference of the International Group for the Psychology of Mathematics Education (pp. 215-222). University of Stellenbosch.

Luna, B., Padmanabhan, A., \& O’Hearn, K. (2010). What has fMRI told us about the development of cognitive control through adolescence? Brain and Cognition, 72, 101-113. https://doi.org/10.1016/j.bandc.2009.08.005 
MacKay, K. J., \& De Smedt, B. (2019). Patterning counts: Individual differences in children's calculation are uniquely predicted by sequence patterning. Fournal of Experimental Child Psychology, 177, 152-165. https://doi.org/10.1016/j.jecp.2018.07.016

Matthews, P. G., Lewis, M. R., \& Hubbard, E. M. (2016). Individual differences in nonsymbolic ratio processing predict symbolic math performance. Psychological Science, 27, 191-202. https://doi.org/10.1177/0956797615617799

McGarvey, L. M. (2012). What is a pattern? Criteria used by teachers and young children. Mathematical Thinking and Learning, 14, 310-337. https://doi.org/10.1080/10986065.2012.717380

McNeil, N. M., \& Fyfe, E. R. (2012). “Concreteness fading” promotes transfer of mathematical knowledge. Learning and Instruction, 22, 440-448. https://doi.org/10.1016/j.learninstruc.2012.05.001

Mielicki, M. K., \& Wiley, J. (2016). Alternative representations in algebraic problem solving: When are graphs better than equations? The fournal of Problem Solving, 9, 3-12. https://doi.org/10.7771/1932-6246.1181

Miller, M. R., Rittle-Johnson, B., Loehr, A. M., \& Fyfe, E. R. (2016). The influence of relational knowledge and executive function on preschoolers' repeating pattern knowledge. Journal of Cognition and Development, 17, 85-104.

https://doi.org/10.1080/15248372.2015.1023307

Nathan, M. J., \& Koedinger, K. R. (2000). An investigation of teachers' beliefs of students' algebra development. Cognition and Instruction, 18, 209-237. https://doi.org/10.1207/S1532690XCI1802_03

National Governors Association Center for Best Practices \& Council of Chief State School Officers. (2010). Common Core state standards mathematics. National Governors Association Center for Best Practices \& Council of Chief State School Officers.

National Mathematics Advisory Panel. (2008). Final report. U.S. Department of Education.

Nguyen, T., Watts, T. W., Duncan, G. J., Clements, D. H., Sarama, J. S., Wolfe, C., \& Spitler, M. E. (2016). Which preschool mathematics competencies are most predictive of fifth grade achievement? Early Childhood Research Quarterly, 36, 550-560.

https://doi.org/10.1016/j.ecresq.2016.02.003

Novick, L. R., \& Holyoak, K. J. (1991). Mathematical problem solving by analogy. fournal of Experimental Psychology: Learning, Memory, and Cognition, 17, 398-415. https://doi.org/10.1037/0278-7393.17.3.398

Paik, J. H., \& Mix, K. S. (2003). US and Korean children's comprehension of fraction names: A reexamination of cross-national differences. Child Development, 74, 144-154. https://doi.org/10.1111/1467-8624.t01-1-00526

Papic, M. M., Mulligan, J. T., \& Mitchelmore, M. C. (2011). Assessing the development of preschoolers' mathematical patterning. fournal for Research in Mathematics Education, 42, 237-269. https://doi.org/10.5951/jresematheduc.42.3.0237

Pasnak, R., Schmerold, K. L., Robinson, M. F., Gadzichowski, K. M., Bock, A. M., O’Brien, S. E., . . Gallington, D. A. (2016). Understanding number sequences leads to understanding mathematics concepts. The fournal of Educational Research, 109, 640-646. https://doi.org/10.1080/00220671.2015.1020911

Peters, E., Tompkins, M. K., Knoll, M. A., Ardoin, S. P., Shoots-Reinhard, B., \& Meara, A. S. (2019). Despite high objective numeracy, lower numeric confidence relates to worse financial and medical outcomes. Proceedings of the National Academy of Sciences of the United States of America, 116, 19386-19391. https://doi.org/10.1073/pnas.1903126116

Reyna, V. F., Nelson, W. L., Han, P. K., \& Dieckmann, N. F. (2009). How numeracy influences risk comprehension and medical decision making. Psychological Bulletin, 135, 943-973. https://doi.org/10.1037/a0017327

Richland, L. E., Holyoak, K. J., \& Stigler, J. W. (2004). Analogy use in eighth-grade mathematics classrooms. Cognition and Instruction, 22, 37-60. https://doi.org/10.1207/s1532690Xci2201_2

Richland, L. E., Zur, O., \& Holyoak, K. J. (2007). Cognitive supports for analogies in the mathematics classroom. Science, 316, 1128-1129. https://doi.org/10.1126/science. 1142103

Ritchie, S. J., \& Bates, T. C. (2013). Enduring links from childhood mathematics and reading achievement to adult socioeconomic status. Psychological Science, 24, 1301-1308. https://doi.org/10.1177/0956797612466268

Rittle-Johnson, B., Fyfe, E. R., Loehr, A. M., \& Miller, M. R. (2015). Beyond numeracy in preschool: Adding patterns to the equation. Early Childhood Research Quarterly, 31, 101-112. https://doi.org/10.1016/j.ecresq.2015.01.005

Rittle-Johnson, B., Fyfe, E. R., McLean, L. E., \& McEldoon, K. L. (2013). Emerging understanding of patterning in 4-year-olds. Journal of Cognition and Development, 14, 376-396. https://doi.org/10.1080/15248372.2012.689897

Rittle-Johnson, B., Zippert, E. L., \& Boice, K. L. (2019). The roles of patterning and spatial skills in early mathematics development. Early Childhood Research Quarterly, 46, 166-178. https://doi.org/10.1016/j.ecresq.2018.03.006

Rivera, F. D. (2010). Visual templates in pattern generalization activity. Educational Studies in Mathematics, 73, 297-328. https://doi.org/10.1007/s10649-009-9222-0 
Rivera, F. D., \& Becker, J. R. (2005). Teacher to teacher: Figural and numerical modes of generalizing in algebra. Mathematics Teaching in the Middle School, 11, 198-203. https://doi.org/10.5951/MTMS.11.4.0198

Schiller, L. K. (2020). Recharging rational number understanding [Unpublished doctoral dissertation]. Columbia University, TC.

Schoenfeld, A. (1995). Report of Working Group 1. In C. B. Lacampagne, W. Blair, \& J. Kaput (Eds.), The algebra initiative colloquium (pp. 11-18). U.S. Department of Education, Office of Educational Research and Improvement.

Sfard, A., \& Linchevski, L. (1994). The gains and the pitfalls of reification-The case of algebra. In P. Cobb (Ed.), Learning mathematics: Constructivist and interactionist theories of mathematical development. https://doi.org/10.1007/978-94-017-2057-1_4

Sidney, P. G., Thompson, C. A., Matthews, P. G., \& Hubbard, E. M. (2017). From continuous magnitudes to symbolic numbers: The centrality of ratio. Behavioral and Brain Sciences, 40, Article e190. https://doi.org/10.1017/S0140525X16002284

Sidney, P. G., Thalluri, R., Buerke, M. L., \& Thompson, C. A. (2019). Who uses more strategies? Linking mathematics anxiety to adults' strategy variability and performance on fraction magnitude tasks. Thinking \& Reasoning, 25, 94-131. https://doi.org/10.1080/13546783.2018.1475303

Sidney, P. G., \& Thompson, C. A. (2019). Implicit analogies in learning: Supporting transfer by warming up. Current Directions in Psychological Science, 28, 619-625. https://doi.org/10.1177/0963721419870801

Sidney, P. G., Thompson, C. A., \& Rivera, F. D. (2019). Number lines, but not area models, support children's accuracy and conceptual models of fraction division. Contemporary Educational Psychology, 58, 288-298. https://doi.org/10.1016/j.cedpsych.2019.03.011

Siegler, R. S., \& Thompson, C. A. (2014). Numerical landmarks are useful-Except when they're not. Fournal of Experimental Child Psychology, 120, 39-58. https://doi.org/10.1016/j.jecp.2013.11.014

Siegler, R. S., Thompson, C. A., \& Schneider, M. (2011). An integrated theory of whole number and fractions development. Cognitive Psychology, 62, 273-296. https://doi.org/10.1016/j.cogpsych.2011.03.001

Singley, A. T. M., \& Bunge, S. A. (2014). Neurodevelopment of relational reasoning: Implications for mathematical pedagogy. Trends in Neuroscience and Education, 3, 33-37. https://doi.org/10.1016/j.tine.2014.03.001

Smith, L. B. (2003). Learning to recognize objects. Psychological Science, 14, 244-250. https://doi.org/10.1111/1467-9280.03439

Soltész, F., Goswami, U., White, S., \& Szűcs, D. (2011). Executive function effects and numerical development in children: Behavioural and ERP evidence from a numerical Stroop paradigm. Learning and Individual Differences, 21, 662-671.

https://doi.org/10.1016/j.lindif.2010.10.004

Son, J. Y., Smith, L. B., \& Goldstone, R. L. (2011). Connecting instances to promote children's relational reasoning. Fournal of Experimental Child Psychology, 108, 260-277. https://doi.org/10.1016/j.jecp.2010.08.011

St Clair-Thompson, H. L., \& Gathercole, S. E. (2006). Executive functions and achievements in school: Shifting, updating, inhibition, and working memory. Quarterly fournal of Experimental Psychology, 59, 745-759. https://doi.org/10.1080/17470210500162854

Stephens, A. C., Ellis, A. B., Blanton, M., \& Brizuela, B. M. (2017). Algebraic thinking in the elementary and middle grades. In J. Cai (Ed.), Compendium of research on mathematics teaching and learning (pp. 386-420). National Council of Teachers of Mathematics.

Szũcs, D., Soltész, F., Jarmi, E., \& Csepe, V. (2007). The speed of magnitude processing and executive functions in controlled and automatic number comparison in children: An electro-encephalography study. Behavioral and Brain Functions, 3, Article 23. https://doi.org/10.1186/1744-9081-3-23

Walkowiak, T. A. (2014). Elementary and middle school students' analyses of pictorial growth patterns. The fournal of Mathematical Behavior, 33, 56-71. https://doi.org/10.1016/j.jmathb.2013.09.004

Warren, E. (2005). Young children's ability to generalise the pattern rule for growing patterns. In H. L. Chick \& J. L. Vincent (Eds.), Proceedings of the 29th conference of the international group for the Psychology of Mathematics Education (pp. 305-312). Melbourne, Australia: PME.

Warren, E., \& Cooper, T. (2007). Repeating patterns and multiplicative thinking: Analysis of classroom interactions with 9-year-old students that support the transition from the known to the novel. fournal of Classroom Interaction, 41, 7-17.

Warren, E., \& Cooper, T. (2008). Generalising the pattern rule for visual growth patterns: Actions that support 8 year olds' thinking. Educational Studies in Mathematics, 67, 171-185. https://doi.org/10.1007/s10649-007-9092-2

White, C. S. (1998). The relationship between young children's analogical reasoning and mathematical learning. Mathematical Cognition, 4, 103-123. https://doi.org/10.1080/135467998387352

Wijns, N., Torbeyns, J., Bakker, M., De Smedt, B., \& Verschaffel, L. (2019). Four-year olds' understanding of repeating and growing patterns and its association with early numerical ability. Early Childhood Research Quarterly, 49, 152-163.

https://doi.org/10.1016/j.ecresq.2019.06.004 
Wijns, N., Torbeyns, J., De Smedt, B., \& Verschaffel, L. (2019). Young children's patterning competencies and mathematical development: A review. In K. Robinson, H. Osana, \& D. Kotsopoulos (Eds.) Mathematical learning and cognition in early childhood (pp. 139-161). Springer.

Wijns, N., Verschaffel, L., De Smedt, B., De Keyser, L., \& Torbeyns, J. (2021). Stimulating preschoolers' focus on structure in repeating and growing patterns. Learning and Instruction, 74, Article 101444. https://doi.org/10.1016/j.learninstruc.2021.101444

Wollman, W. (1983). Determining the sources of error in a translation from sentence to equation. fournal for Research in Mathematics Education, 14, 169-181. https://doi.org/10.2307/748380

Zippert, E. L., Clayback, K., \& Rittle-Johnson, B. (2019). Not Just IQ: Patterning Predicts Preschoolers' Math Knowledge Beyond Fluid Reasoning. Fournal of Cognition and Development, 20, 752-771. https://doi.org/10.1080/15248372.2019.1658587 


\section{Appendices}

\section{Appendix A: Patterning Problems}

Note: Participants were shown the problems with one of the three presentations below (depending on condition).

\section{Patterning Problem 1}

Consider the following pattern.

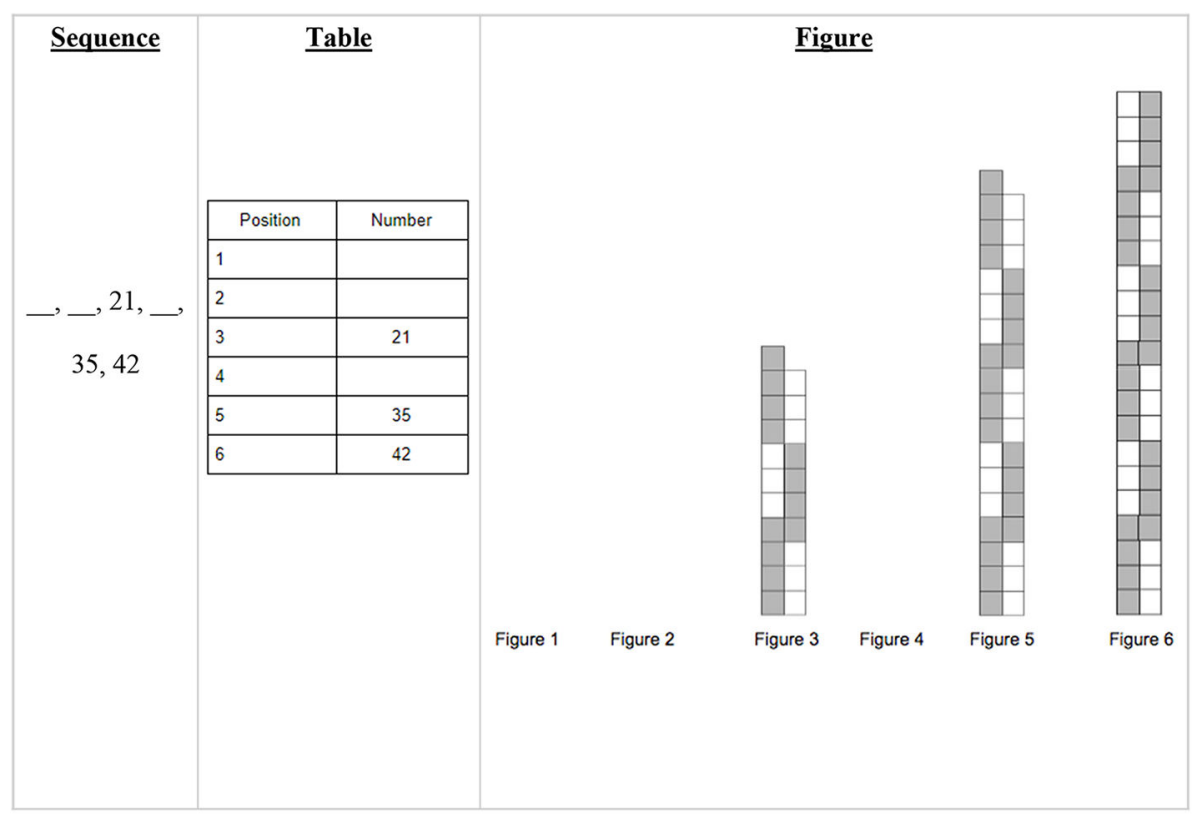

Near Extension Task: Think about how the pattern is changing. What are the first, second, and fourth numbers/figures in the pattern? How do you know?

Matching Task: Jim's rule was "add 3+4 to the previous figure," and Karen's rule was "add 14 each time." Who is correct? How do you know?

Far Extension Task: What would the 35th number/figure be? How do you know? 


\section{Patterning Problem 2}

Consider the following pattern.

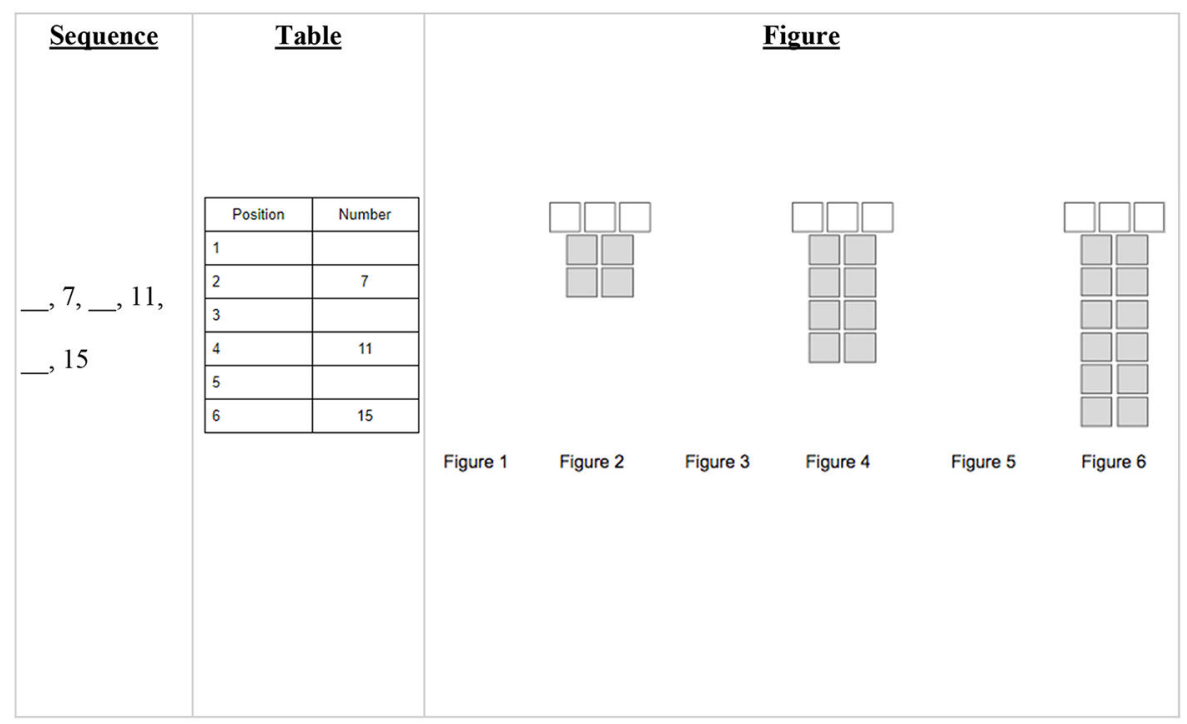

Near Extension Task: Think about how the pattern is changing. What are the first, third, and fifth numbers/figures in the pattern? How do you know?

Matching Task: Jackie's rule was "add 4 each time," and Derek's rule was "add 2 each time." Who is correct? How do you know? Far Extension Task: What would the 43rd number/figure be? How do you know?

\section{Patterning Problem 3}

Consider the following pattern.

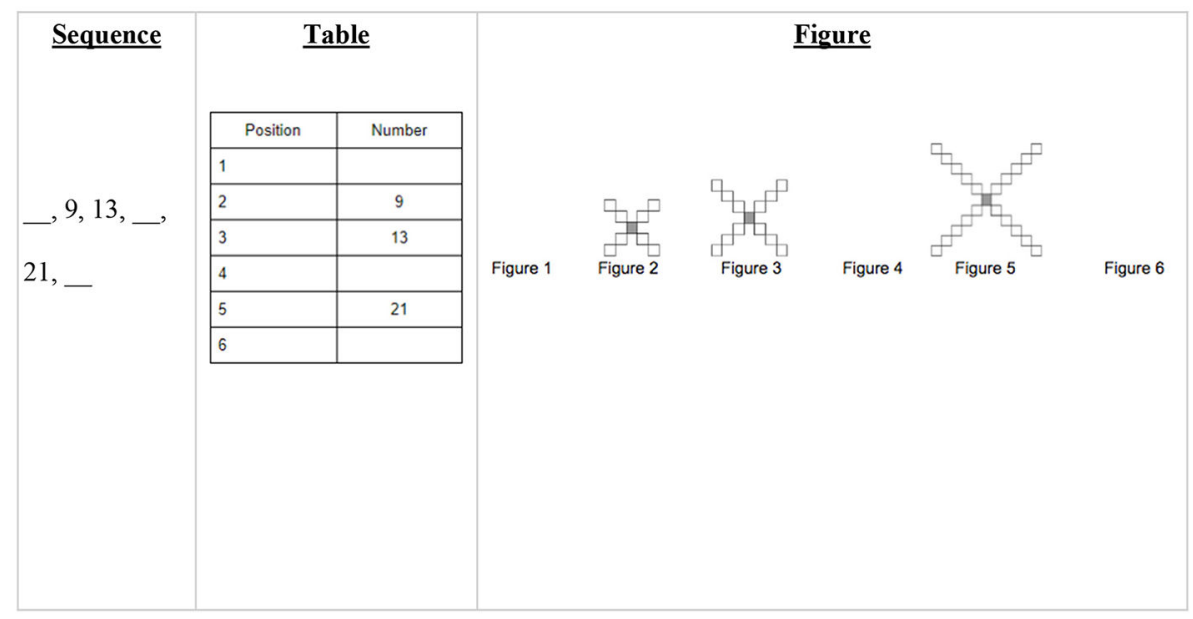

Near Extension Task: Think about how the pattern is changing. What are the first, fourth, and sixth numbers/figures in the pattern? How do you know?

Matching Task: Matt's rule was "count by $4 \mathrm{~s}$ ” and Jayden's rule was "add 5 each time." Who is correct? How do you know? Far Extension Task: What would the 37th number/figure be? How do you know? 


\section{Appendix B: Transfer Problems}

\section{Transfer Problem 1}

Jenna just got a new book, and she starts reading the same amount every day. After the first day, she has 182 pages left to read. After the third day, she has 168 pages left to read. After the fifth day, she has 154 pages left to read.

Near Extension Task: Think about Jenna's reading pattern. If Jenna read the same amount every day, how many pages did she have left after the second day? What about after the fourth day? How many pages did she have left after the sixth day? How do you know? Matching Task: When talking about the book with her friends, Jenna says, "to find how many pages I have left, I subtract 10 from the day before, then add 3", but her friend Ashley says, "you read 6 pages each day." Who is correct, Jenna or Ashley? How do you know?

Far Extension Task: Jenna wants to know how many pages she will have left if she keeps reading for 3 weeks (21 days). How many pages would you tell Jenna she will have left after 3 weeks? How do you know?

Reversal Task: How many days will it take Jenna to finish the book? How do you know?

\section{Transfer Problem 2}

Nathan already has some baseball cards, but he wants to start collecting more. When Nathan buys 1 pack of cards, he has 36 total cards in his collection. After buying his second pack of cards, he has 60 cards total. When Nathan buys his third pack of cards, he has 84 cards in all.

Near Extension Task: Think about how Nathan's collection of baseball cards growing. How many total baseball cards will Nathan have after buying his fourth pack of cards? What about after buying his fifth pack? How many cards will he have in total after buying his sixth pack? How do you know?

Matching Task: Nathan's dad says, "each time you get another pack of cards, your collection doubles", but his mom says, "each time you get another pack of cards, your collection gets bigger by 24 cards." Which of Nathan's parents is correct? How do you know?

Far Extension Task: Nathan wants to know how many baseball cards he will have after he buys 20 packs of cards. How many cards would you tell Nathan he will have if he buys 20 packs of cards? How do you know?

Reversal Task: If Nathan has 780 cards total, how many packs of cards has he bought? How do you know?

\section{Appendix C: Task-Level Performance and Coding}

\section{Table C1}

Proportion Correct for Near Extension Tasks by Condition for Session 1 Problems and Transfer Story Problems

\begin{tabular}{|c|c|c|c|c|c|c|}
\hline \multirow[b]{2}{*}{ Problem Type / Underlying Function } & \multicolumn{2}{|c|}{ Sequence } & \multicolumn{2}{|c|}{ Table } & \multicolumn{2}{|c|}{ Figure } \\
\hline & $\boldsymbol{M}$ & $S D$ & $\boldsymbol{M}$ & $S D$ & $M$ & $S D$ \\
\hline \multicolumn{7}{|l|}{ Session 1 (presented with patterns) } \\
\hline $\begin{array}{l}\mathrm{y}=7 \mathrm{x} \\
\text { (proportional) }\end{array}$ & .94 & .22 & .95 & .23 & .48 & .44 \\
\hline $\begin{array}{l}y=2 x+3 \\
\text { (non-proportional) }\end{array}$ & .92 & .23 & .74 & .41 & .85 & .37 \\
\hline $\begin{array}{l}\mathrm{y}=4 \mathrm{x}+1 \\
\text { (non-proportional) }\end{array}$ & .95 & .95 & .74 & .42 & .83 & .37 \\
\hline \multicolumn{7}{|c|}{ Transfer (presented as story problems without patterns) } \\
\hline $\begin{array}{l}y=189-7 x \\
\text { (non-proportional) }\end{array}$ & .70 & .42 & .54 & .49 & .57 & .47 \\
\hline $\begin{array}{l}\mathrm{y}=24 \mathrm{x}+12 \\
\text { (non-proportional) }\end{array}$ & .67 & .41 & .81 & .34 & .53 & .49 \\
\hline
\end{tabular}

Note. Each near extension task had 3 responses (one for each missing stage of the pattern), so each participant's proportion correct was out of 3 possible. 


\section{Table C2}

Proportion of Participants Who Responded Correctly to Each Matching Item by Condition for Session 1 Problems and Transfer Story Problems

\begin{tabular}{|c|c|c|c|}
\hline Problem Type / Underlying Function & Sequence & Table & Figure \\
\hline \multicolumn{4}{|l|}{ Session 1 (presented with patterns) } \\
\hline $\begin{array}{l}\mathrm{y}=7 \mathrm{x} \\
\text { (proportional) }\end{array}$ & .96 & .90 & .75 \\
\hline $\begin{array}{l}y=2 x+3 \\
\text { (non-proportional) }\end{array}$ & .91 & .74 & .85 \\
\hline $\begin{array}{l}y=4 x+1 \\
\text { (non-proportional) }\end{array}$ & .86 & .79 & .90 \\
\hline \multicolumn{4}{|c|}{ Transfer (presented as story problems without patterns) } \\
\hline $\begin{array}{l}y=189-7 x \\
\text { (non-proportional) }\end{array}$ & .68 & .74 & .70 \\
\hline $\begin{array}{l}y=24 x+12 \\
\text { (non-proportional) }\end{array}$ & .86 & .95 & .90 \\
\hline
\end{tabular}

\section{Table C3}

Proportion of Participants Who Responded Correctly to Each Far Extension Item by Condition for Session 1 Problems and Transfer Story Problems

\begin{tabular}{|c|c|c|c|}
\hline Problem Type / Underlying Function & Sequence & Table & Figure \\
\hline \multicolumn{4}{|l|}{ Session 1 (presented with patterns) } \\
\hline $\begin{array}{l}\mathrm{y}=7 \mathrm{x} \\
\text { (proportional) }\end{array}$ & .77 & .79 & .30 \\
\hline $\begin{array}{l}y=2 x+3 \\
\text { (non-proportional) }\end{array}$ & .05 & .11 & .40 \\
\hline $\begin{array}{l}y=4 x+1 \\
\text { (non-proportional) }\end{array}$ & .05 & .11 & .50 \\
\hline \multicolumn{4}{|c|}{ Transfer (presented as story problems without patterns) } \\
\hline $\begin{array}{l}\mathrm{y}=189-7 \mathrm{x} \\
(\text { non-proportional) }\end{array}$ & .27 & .16 & .15 \\
\hline $\begin{array}{l}y=24 x+12 \\
\text { (non-proportional) }\end{array}$ & .32 & .16 & .15 \\
\hline
\end{tabular}

\section{Table C4}

Proportion of Participants Who Responded Correctly to Each Transfer Reversal Item by Condition

\begin{tabular}{lccc}
\hline Underlying Function & Sequence & Table & Figure \\
\hline $\mathrm{y}=189-7 \mathrm{x}$ & .48 & .33 & .19 \\
(non-proportional) & & & .25 \\
\hline $\mathrm{y}=24 \mathrm{x}+12$ & .40 & .35 & \\
(non-proportional) & & & .25 \\
\hline
\end{tabular}




\section{Table C5}

Proportion of Participants in Each Condition Coded as Errors, "No Rule", or "Other"

\begin{tabular}{|c|c|c|c|}
\hline Strategy by Task & Sequence & Table & Figure \\
\hline \multicolumn{4}{|c|}{ Proportional } \\
\hline \multicolumn{4}{|l|}{ Near Extension } \\
\hline No Rule & .14 & .00 & .45 \\
\hline Other & .00 & .05 & .15 \\
\hline Computation Error & .05 & .00 & .10 \\
\hline Missed Step Error & .00 & .00 & .10 \\
\hline \multicolumn{4}{|l|}{ Far Extension } \\
\hline No Rule & .00 & .00 & .35 \\
\hline Other & .09 & .00 & .05 \\
\hline Computation Error & .14 & .16 & .15 \\
\hline Missed Step Error & .00 & .00 & .00 \\
\hline
\end{tabular}

\section{Non-Proportional}

\section{Near Extension \\ Other \\ Computation Error \\ Missed Step Error \\ Far Extension \\ No Rule \\ Other \\ Computation Error \\ Missed Step Error}

\begin{tabular}{lll}
.11 & .08 & .20 \\
.00 & .11 & .05 \\
.02 & .11 & .00 \\
.00 & .05 & .08 \\
& & \\
.05 & .00 & .18 \\
.14 & .11 & .18 \\
.12 & .00 & .08 \\
.00 & .00 & .08 \\
\hline
\end{tabular}

\section{Transfer}

\begin{tabular}{|c|c|c|c|}
\hline \multicolumn{4}{|l|}{ Near Extension } \\
\hline No Rule & .09 & .05 & .05 \\
\hline Other & .11 & .05 & .10 \\
\hline Computation Error & .16 & .11 & .20 \\
\hline Missed Step Error & .30 & .24 & .35 \\
\hline \multicolumn{4}{|l|}{ Far Extension } \\
\hline No Rule & .02 & .05 & .05 \\
\hline Other & .14 & .13 & .18 \\
\hline Computation Error & .09 & .03 & .08 \\
\hline Missed Step Error & .07 & .00 & .05 \\
\hline \multicolumn{4}{|l|}{ Reversal } \\
\hline No Rule & .05 & .16 & .18 \\
\hline Other & .16 & .11 & .08 \\
\hline Computation Error & .14 & .13 & .20 \\
\hline
\end{tabular}

\section{Additional Analyses of Non-Target Strategies}

The instances of No Rule and Other codes were summed separately for patterning problems and transfer problems. No condition differences were observed for Other codes for either patterning problems, $F(2,60)=0.11, p=.89$, or transfer problems, $F(2,60)=$ $0.14, p=.87$. In addition, no condition differences were observed for No Rule codes in transfer problems, $F(2,60)=0.52, p=.60$. Strategies that involved errors were summed across patterning problems and transfer problems. No condition differences emerged for Computation Errors on patterning problems, $F(2,60)=0.02, p=.98$, or transfer problems, $F(2,60)=1.12, p=.33$, or for Missed Step Errors on patterning problems, $F(2,60)=0.82, p=.45, \eta_{\mathrm{p}}^{2}=.10$, or transfer problems, $F(2,60)=0.82, p=.45$. 


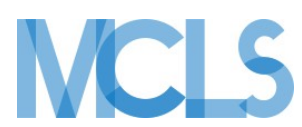

Journal of Numerical Cognition (JNC) is an official journal of the Mathematical Cognition and Learning Society (MCLS).

\section{(P) leibniz-psychology.org}

PsychOpen GOLD is a publishing service by Leibniz Institute for Psychology (ZPID), Germany. 